\title{
Effects of Salvia miltiorrhiza on CNS Neuronal Injury and Degeneration: A Plausible Complementary Role of Tanshinones and Depsides*
}

Authors

Affiliations
Laura Bonaccini ${ }^{1}$, Anastasia Karioti ${ }^{2}$, Maria Camilla Bergonzi ${ }^{1}$, Anna Rita Bilia ${ }^{1}$

${ }^{1}$ Department of Chemistry University of Florence, Sesto Fiorentino, Florence, Italy

${ }^{2}$ Department of Pharmacy, Division of Pharmocognosy-Pharmacology, University Campus, Thessaloníki, Greece
Key words

- Salvia miltiorrhiza

- Lamiaceae

- tanshinones and depsides

- CNS neuronal injury and degeneration

- in vivo studies

- biochemical mechanisms

- pharmacokinetics received March 4, 2015

revised May 17, 2015

accepted May 19, 2015

Bibliography

DOI http://dx.doi.org/

10.1055/s-0035-1546196

Published online July 17, 2015

Planta Med 2015; 81:

1003-1016 @ Georg Thieme

Verlag KG Stuttgart · New York .

ISSN 0032-0943

Correspondence

Prof. Dr. Anna Rita Bilia

Department of Chemistry

University of Florence

Via Ugo Schiff 6

50019 Sesto Fiorentino, Florence

Italy

Phone: + 390554573708

ar.bilia@unifi.it

\section{Abstract}

$\nabla$

Salvia miltiorrhiza is a very important herbal drug of traditional Chinese medicine. Bioactive constituents are represented by two main groups of secondary metabolites, the lipophilic diterpenic quinones known as tanshinones and the hydrophilic depsides known as salvianolic acids. S. miltiorrhi$z a$ extracts and single constituents have been shown to have positive effects in central nervous system neuronal injury and degeneration in several animal models by various biological mechanisms. Both tanshinones and depsides protect against $\beta$-amyloid-induced toxicity, but their mechanisms are complementary due to their different structure, the lipophilic tanshinones and the hydrophilic depsides. A number of anti-inflammatory mechanisms is also reported for both tanshinones and depsides. Common mechanisms are the effects on cytokines, inducible nitric oxide synthase, and glial fibrillary acidic protein. In addition, depsides are inhibitors of nitric oxide and cyclooxygenase-2, while tanshinones inhibit hypoxia-inducible factor- $1 \alpha$ and nuclear factor kappa $\beta$. Both constituents can also modulate the protection of the central nervous system from oxidative stress with different but complementary mechanisms: tanshinones can enhance the activities of superoxide dismutase and glutathione peroxidase, while depsides can decrease reactive oxygen species.

Furthermore, neuronal death underlies the symptoms of many human neurological disorders, including Alzheimer's, Parkinson's, and Huntington's diseases, stroke, and amyotrophic lateral sclerosis. Both classes of constituents can enhance the antiapoptotic B-cell leukemia protein-2 family members and decrease the translocation of cyto-

* Dedicated to Professor Dr. Dr. h.c. mult. Adolf Nahrstedt on the occasion of his 75th birthday. chrome c, and, in addition, depsides decrease caspase-3 and intracellular $\mathrm{Ca}^{2+}$. Again, both classes of constituents have an activity on vascular endothelial growth factor but it is opposite, whereas tanshinones are inhibitors of acetylcholinesterase.

Besides the extensive studies reporting on the biological mechanisms of depsides and tanshinones, pharmacokinetics studies are still very limited and not conclusive, especially for brain distribution. Further research is warranted to address the mechanisms of the multitarget actions of S. miltiorrhiza constituents and to translate this knowledge into clinical practice.

\section{Abbreviations \\ $\nabla$ \\ AChE: acetylcholinesterase \\ AD: Alzheimer's disease \\ APP: $\quad$ amyloid precursor protein \\ Akt: $\quad$ protein kinase $B$ \\ $\mathrm{A} \beta$ : $\quad \beta$-amyloid \\ Bax: $\quad$ Bcl2-associated $X$ protein \\ BBB: blood-brain barrier \\ Bcl-2: B-cell leukemia protein \\ BDNF: brain-derived neurotrophic factor \\ BPRP: brain-pancreas relative protein \\ CA1: hippocampal CA1 region \\ Cdk5: $\quad$ cyclin-dependent kinase 5 \\ CMM: $\quad$ Chinese materia medica \\ CNS: central nervous system \\ COX-2: cyclooxygenase-2 \\ CTS: cryptotanshinone \\ DTSI: dihydrotanshinone I \\ EPO: erythropoietin \\ ER: estrogen receptor}

ERK1/2: extracellular signal-regulated kinase 1 and 2

GFAP: glial fibrillary acidic protein

GSH-Px: glutathione peroxidase

GSK-3 $\beta$ : glycogen synthase kinase-3 beta 
HD: herbal drug

HDP: herbal drug preparation

HIF-1 $\alpha$ : hypoxia-inducible factor- $1 \alpha$

HMGB1: high mobility group box 1

HO-1: $\quad$ heme oxygenase-1

IB4: isolection B4

ICAM-1: intercellular adhesion molecule-1

IGF-I: insulin-like growth factor-I

IL: interleukin

iNOS: inducible nitric oxide synthase

i.p. intraperitoneal

i.v. intravenous

I/R: ischemia/reperfusion

JAK2: $\quad$ janus kinase 2

LA: lithospermic acid

MDA: malondialdehyde

MIF: migration inhibitory factor

MMPs: matrix metalloproteinases

MPP+: 1-methyl-4-phenylpyridinium ion

mTORC1: mammalian target of rapamycin complex 1

NF- $k$ B: $\quad$ nuclear factor $k$ B

NOS: $\quad$ nitric oxide synthase

Nrf2: $\quad$ NF-E2-related factor 2
OX-42: rat monoclonal anti-CD11b

RA: rosmarinic acid

ROS: $\quad$ reactive oxygen species

SalA: $\quad$ salvianolic acid $A$

SalB: $\quad$ salvianolic acid B

SOD: $\quad$ superoxide dismutase

SOD1: Zn-superoxide dismutase

SOD2: Mn-superoxide dismutase

STAT3: $\quad$ signal transducers and activators of transcription 3

T-AOC: total antioxidant capability

TCM: $\quad$ traditional Chinese medicine

TGF- $\beta 1$ : transforming growth factor

TLR: $\quad$ toll-like receptors

TNF- $\alpha$ : tumor necrosis factor- $\alpha$

Trx: $\quad$ thioredoxin

TSI: tanshinone I

TSIIA: tanshinone IIA

TSIIB: tanshinone IIB

TUNEL: terminal deoxyribonucleotidyl transferase-mediated dUTP-biotin nick end labeling

VEGF: vascular endothelial growth factor

ZO-1: $\quad$ proteins zonula occludens-1

\section{Introduction}

$\nabla$

Salvia miltiorrhiza Bunge (Lamiaceae) is a very famous HD of the TCM. It first appeared in the Shennong Bencao Jing (ca. 100 A.D.) among the most important medicinal materials, i.e., cinnabar (mineral) ginseng (herb) and the mushroom ganoderma [1].

The HD consists of the dried rhizomes and roots (Salviae miltiorrhizae Radix et Rhizoma), which have a particularly intense red color according to the epithet miltiorrhiza, which means "red juice extracted from a root". The herb is a deciduous perennial plant rising up to $30-60 \mathrm{~cm}$ high, and is native to China and Japan where it grows at an altitude between 90-1200 m. Leaves are simple or divided, depending on their position on the stem. Flower petals are purple or blue held within a dark purple calyx [2]. The common English names of S. miltiorrhiza are "Chinese sage" or "red sage" [3]. Nevertheless, this plant is also generally known in the Western world with the Pinyin names Danshen (丹參), Chi Shen (赤参), and Zi Danshen (紫丹参). The name Danshen carries much meaning. Dan is the term used to describe cinnabar which is called Dansha (丹砂) or Zhusha (朱砂), Sha being the sand (depicting the small crystals of the mineral), probably related to the dark red color of $S$. miltiorrhiza roots, or just because cinnabar is one of the top substances of CMM, therefore expressing the great value of S. miltiorrhiza. Similarly, the word Shen refers to ginseng or Renshen (人参), the most important herb of CMM [1].

Salviae miltiorrhizae Radix et Rhizoma has a longstanding use in TCM to treat bleeding disorders (e.g., menstrual bleeding) and blood stasis [4], and only during the 20th Century it became known for its blood-vitalizing properties thanks to a famous physician, Qin Bowei, who recommended this HD for heart pain, reporting its efficacy in a series of cases of angina pectoris [5].

Several studies in the 1980s confirmed the therapeutic potential of this HD in cardiovascular disorders, including stroke [6,7]. In the successive decades, the number of pharmacological and clinical studies grew rapidly proving not only cardiovascular properties but widespread activities in several pathologies. Many interesting, promising therapeutic applications of S. miltiorrhiza ex- tracts or single constituents have now appeared in the literature and include acute ischemic stroke [8,9], AD [10-12], osteoporosis [13], atherosclerosis [14], fulminant hepatic failure [15], and malignant gliomas [16].

In virtue of having few side effects, $S$. miltiorrhiza and its single constituents have been widely and successfully used in clinics in China, Korea, Japan, and other Asian countries for the treatment of heart and cerebrovascular disease, hepatitis, hepatocirrhosis, neuroasthenic insomnia, cancer, chronic renal failure, and dysmenorrhea $[1,2,4]$. The great popularity of this plant has contributed to its increasing use in the United States and in many European countries in the form of various dietary supplements claiming amazing benefits, especially neuroprotection and improved cognition.

This paper aims to review the possible role of Salviae miltiorrhizae Radix et Rhizoma against CNS neuronal injury and degeneration, based on the analysis of in vivo studies and biochemical mechanisms involved in the activity.

\section{Characteristic Constituents of Salviae milthiorrhizae Radix et Rhizoma and Their Content in the Herbal Drug and Preparations $\nabla$}

The root of S. miltiorrhiza contains two main groups of secondary metabolites [2], lipophilic diterpenic quinones called tanshinones and hydrophilic depsides, generally known as salvianolic acids. Tanshinones belong to the class of abietane-type norditerpenoid quinones. Due to the quinone skeleton, they have an intense orange-red color, which is responsible for the typical tint of the roots. Main representative tashinones are TSI, TSIIA, TSIIB, CTS, and DTSI, whose structures are reported in $\bullet$ Fig. 1. The total tanshinone content of roots and rhizome is about $1 \%$, with TSI and II and CTS being the highest amounts [2].

The hydrophilic constituents depsides (up to 4-5\% dried HD) are derivatives obtained by condensation of caffeic acid units or by combination of caffeic acid plus 3,4-dihydroxyphenyl lactic acid 
<smiles>Cc1coc2c1C(=O)C(=O)c1c-2ccc2ccccc12</smiles>

1<smiles>CC1COC2=C1C(=O)C(=O)c1c2ccc2ccccc12</smiles>

4

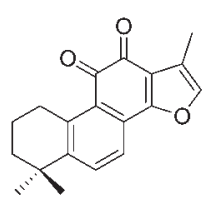

2

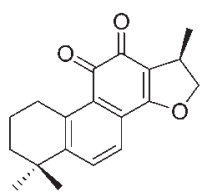

5
Fig. 1 Chemical structures of the main tanshinones found in S. miltiorrhiza: $\mathbf{1}$ tanshinone I; $\mathbf{2}$ tanshinone IIA; $\mathbf{3}$ tanshinone IIB; $\mathbf{4}$ dihydrotanshinone I; 5 cryptotanshinone.

in the form of dimers, trimmers, and tetramers. Main representatives are SalB and its salts with magnesium and ammonium potassium (magnesium lithospermate and ammonium-potassium lithospermate) and SalA, while LA and RA are generally present in lower amounts. Their structures are reported in 0 Fig. 2. Fingerprint analysis of $S$. miltiorrhiza from different regions of China has shown that lipophilic and hydrophilic constituents vary depending on the habitat $[17,18]$.

According to the Pharmacopoeia of the People's Republic of China [3], both TSIIA and SalB are estimated for quality control of the HD and its preparations. The content of TSIIA in Salviae miltiorrhizae Radix et Rhizome should not be less than $0.20 \%$, while SalB should be not less than $3.0 \%$. A similar content is proposed in a draft monograph of the Pharmaeuropa; the dried HD should contain a minimum of $3.0 \%$ SalB and a minimum of $0.12 \%$ TSIIA.
In TCM, the dosage of the HD is 9-15 g daily, recommended in the decoction form [3]. By contrast, currently, a new form of HDP, the granules, has been developed in the major TCM hospitals in mainland China, Hong Kong, and Taiwan. These granules are concentrated herbal extract preparations, whose constituents are 35 times those present in the water decoctions.

Both the traditional decoctions and innovative granules are reported to contain the two classes of constituents, the expected water-soluble depsides and the tanshinones, which are strongly lipophilic molecules. In particular, lyophilized decoctions are reported to contain $27.9-71.8 \mathrm{mg} / \mathrm{g}$ of SalB, up to $9 \mathrm{mg} / \mathrm{g}$ of other depsides, and up to $0.70 \mathrm{mg} / \mathrm{g}$ of tashinones; by contrast, granules contain $2.56-67.5 \mathrm{mg} / \mathrm{g}$ of SalB, up to $20 \mathrm{mg} / \mathrm{g}$ of other depsides, and up to $7.70 \mathrm{mg} / \mathrm{g}$ of tashinones [19].

\section{Effects of Salvia miltiorrhiza Extracts and Single Constituents on Central Nervous System Neuronal Injury and Degeneration: In Vivo Studies}

S. miltiorrhiza extracts and single constituents have been shown to have positive effects in CNS neuronal injury and degeneration in several animal models. Among the models used are cerebral injury, streptozocin-induced diabetes, hyperlipidemia, and an Alzheimer's model ( $A \beta$ peptide injection), while the methods of evaluation of the neurological functions include behavioral tests (Morris water maze, Y maze, and passive avoidance tests), neurological deficits score, and specific histological and biochemical investigations (measurement of the brain water content, infarction size, and apoptotic neurons, BBB disruption, and Ig invasion of brain tissues).

Remarkably, despite decoction as the most common preparation used in TCM, most of the studies on animals are carried out using single constituents (both depsides and tanshinones), rather than the phytocomplex. Hence, protective effects in CNS neuronal injury and degeneration have been evidenced for both hydrophilic

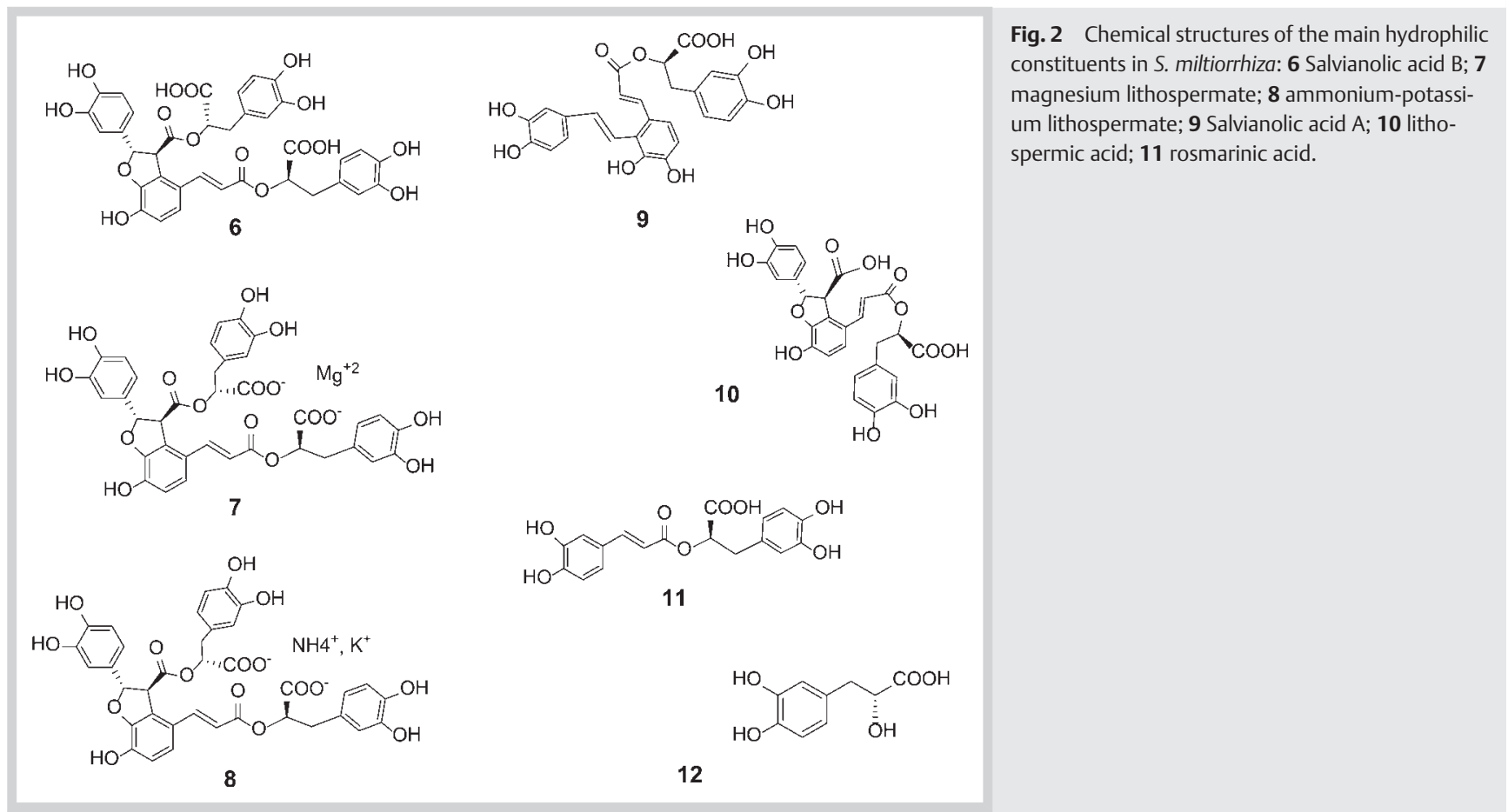


and lipophilic constituents. In all studies, cognitive impairment was improved and neurological deficits were reduced, suggesting that both tanshinones and despsides were able, even poorly, to pass the BBB and exert their therapeutical effect.

Tanshinones, being lipophilic constituents, are administered orally [20] or intraperitoneally [21-27]. After $10-20 \mathrm{mg} / \mathrm{kg}$, i.p. injections are effective in reducing infarct size, edema, and cell damage in models of cerebral ischemia. A single paper [20] is related to an Alzheimer's model of memory impairment, and after the administration of $15 \mathrm{mg} / \mathrm{kg} /$ day per os, there is an improvement of spatial learning and memory and a decrease in amyloid plaque. Additionally, a nanoformulation based on pegylated-albumin nanoparticles given intravenously, prolongs circulation time and increases plasma concentration compared with the unformulated TIIA. A biodistribution and brain uptake study confirmed that CBSA-PEG-TIIA-NPs possessed better brain delivery efficacy with a high drug accumulation and a fluorescence quantitative level in the brain. The nanoparticles effectively reduced infarction volume, neurological dysfunctions, neutrophils infiltration, and neuronal apoptosis. Similar models of CNS trauma have been investigated with hydrophilic depsides, which are administered intravenously [28-30] or orally [31-34]. Similar doses were used by i.v. administration or per os (10-60 mg/kg), with all the cases having positive outcomes and, also, lower dosages.

From the above results, the fact that such different compounds having remarkable different structures, sizes, and polarity can act in the same way in CNS neuronal injury and degeneration it is quite extraordinary. Additionally, it is noteworthy that SalB [30,32-34], a tetramer of caffeic acid, caffeic acid dimer [29], and the smaller analog danshensu (3,4-dihydroxyphenyllactic acid) $[28,31]$ are all effective. Nevertheless, due to the different molecular weights of the constituents, doses of the caffeic acid dimer and danshensu are, respectively, twice and four times that of SalB.

The available literature data are reported in $\bigcirc$ Tables 1 and 2, organized according to the nature of the two classes of constituents, hydrophilic (depsides) and lipophilic ones (tanshinones).

\section{Biochemical Mechanisms of Tanshinones and Depsides in Central Nervous System Neuronal Injury and Degeneration \\ $\nabla$}

\section{Effects of tanshinones}

A number of very recent studies have shown that tanshinones display a promising protective effect on neuron cells. TSI, TSIIA, and CTS are the most abundant components in S. miltiorrhiza and studies have been principally focused to these constituents.

\section{Tanshinone IIA}

Chen and coworkers [37] showed that TSIIA treatment reduced the number of degenerated neurons, significantly $(p<0.05)$ increased the number of intact neurons, and inhibited cerebral apoptosis determined by TUNEL staining [37]. TSIIA decreased the expression of caspase- 3 and caspase- 8 and these results were proportional to the dose of TSIIA used [27].

TSAII reduced the $A \beta_{25-35}$-induced increase of caspase- 3 activity and reduced the cytochrome $\mathrm{C}$ translocation into cytosol from mitochondria, protecting it from mitochondrial abnormalities [27]. In addition, TSIIA increased the expression of Bcl-2 in the ischemic cortex in TSIIA-treated ischemia groups and prevented an increase in the $\mathrm{Bax} / \mathrm{Bcl}-2$ ratio induced by neuronal damage [38].
Qian and coworkers [39] confirmed the neuroprotective effects of TSIIA on cultured cortical neurons treated with $A \beta_{1-42}$, which decreased the antiapoptotic protein $\mathrm{Bcl}-\mathrm{xL}$ and the level of $\mathrm{Bcl}-\mathrm{xL}$ mRNA expression, while the Bcl-xS proapoptotic protein and mRNA did not exhibit any significant alteration [39].

Shi and coworkers [40] elucidated the neuroprotective effects of TSAII against $A \beta_{25-35}$-induced cytotoxicity and detected the association of this protective effect with calpain and the p35/Cdk5 pathway. TSAII increased the viability of neurons, decreased the expression of phosphorylated tau in neurons induced by $A \beta_{25}$ 35 , maintained the normal expression of p35 on peripheral membranes, and decreased p25 expression in the cytoplasm. TanIIA also inhibited the translocation of $\mathrm{Cdk} 5$ from the nucleus into the cytoplasm of primary neurons induced by $\mathrm{A} \beta_{25-35}$.

Fan and coworkers [41] demonstrated that TSAII exerts anti-inflammatory effects by inhibition of inflammation cytokine (IL$1 \beta$, IL- 6 , and TNF- $\alpha$ ) expression via the ER-dependent pathway and inhibition of iNOS gene expression and NO production. Proinflammatory cytokines have been implicated in the disruption of the BBB and the invasion of inflammatory cells into the CNS [41].

TSAII suppressed the expression of proinflammatory cytokines TNF- $\alpha$ and IL- 8 , upregulated the expression of the anti-inflammatory cytokine IL-10, and increased the TGF- $\beta 1$ level. In the ischemic brain, TSAII inhibited the mRNA expressions of GFAP, MMP-9, COX-2, p38MAPK, and JNK, downregulated the protein levels of GFAP, MMP-9, and COX-2, and decreased the phosphorylation of p38MAPK and JNK [35].

Chen and coworkers [42] suggested that neuroprotective effect of TSIIA might occur through the downregulation of macrophage MIF expression in neurons. MIF is a proinflammatory cytokine derived from many cell types. After activation of NF- $k$ B, MIF induces the production of subsequent cytokines. NF- $k$ B plays an important role in neuron survival, as the persistent activation of NF- $k B$ renders neurons vulnerable. TSIIA can inhibit MIF expression, NF- $k$ B activity, and the release of cytokines [42].

Wang and coworkers [22] substantiated the anti-inflammatory properties of TSAII in cerebral ischemia through the downregulation of HMGB1, the translocation from the nucleus to the cytoplasm of RAGE, TLR4, and NF- $k$ B, and the upregulation claudin-5 expression.

Moreover, exposure of cortical neurons to $30 \mu \mathrm{M} \mathrm{A} \beta_{25-35}$ caused decreased activities of SOD and GSH-Px as well as increased levels of MDA production, while the pretreatment with TSAII attenuated the changes in SOD, GSH-Px, and MDA induced by the treatment of $A \beta_{25-35}$ [24].

Tang and coworkers [25] reported that the mRNA expression levels of $\operatorname{Tr} x-1$ and $\operatorname{Trx}-2$ around the ischemia area were significantly increased $(p<0.05)$ in a brain transient ischemia model created by the blockage of the middle cerebral artery. Trx- 1 and Trx- 2 expression levels in the TSIIA group were increased when compared with the control groups. TSIIA exerted a protective effect on nerve cells through free-radical resistance.

Furthermore, it is reported that TSAII has protective effects on the BBB, suppresses the expression of ICAM-1, matrix metalloproteinase-9 (MMP-9), and inhibites the degradation of tight junction ZO-1 and occludin [25].

Through a series of in vitro experiments, Xing and coworkers [43] found that TSAII can inhibit cell migration and invasion that was associated with the suppression of the VEGF/VEGFR2 pathway and regulation of MMP-2/-9 secretion in the vascular endothelial cell by TSAII [44]. 
Table 1 In vivo studies of the lipophilic constituents of S. miltiorrhiza.

\begin{tabular}{|c|c|c|c|c|c|c|}
\hline $\begin{array}{l}\text { Type of constituent/ } \\
\text { extract }\end{array}$ & Animals & $\begin{array}{l}\text { Model of CNS } \\
\text { trauma }\end{array}$ & $\begin{array}{l}\text { Evaluation of CNS } \\
\text { parameters }\end{array}$ & Treatment & Outcome & Reference \\
\hline $\begin{array}{l}\text { Cryptotanshinone \& } \\
\text { tanshinone I }\end{array}$ & $\begin{array}{l}\text { Male Mongo- } \\
\text { lian gerbils }\end{array}$ & $\begin{array}{l}\text { transient cerebral } \\
\text { ischemia }\end{array}$ & $\begin{array}{l}\text { biochemical histo- } \\
\text { logical examination }\end{array}$ & 10 mg/kg (i.p.) & $\begin{array}{l}\text { less damaged cells and } \\
\text { neuronal nuclei the hip- } \\
\text { pocampal region CA1; } \\
\text { also gliosis was blocked }\end{array}$ & [21] \\
\hline Cryptotanshinone & $\begin{array}{l}\text { APP/PS1 } \\
\text { transgenic } \\
\text { mice }\end{array}$ & $\begin{array}{l}\text { Alzheimer's } \\
\text { model - memory } \\
\text { impairement }\end{array}$ & Morris water maze & $\begin{array}{l}5,15 \text {, and } 30 \mathrm{mg} / \mathrm{kg} / \\
\text { day (os, once a day } \\
\text { for } 4 \text { months) }\end{array}$ & $\begin{array}{l}\text { improved spatial learn- } \\
\text { ing and memory, and } \\
\text { decreased amyloid } \\
\text { plaque }\end{array}$ & [20] \\
\hline Tanshinone IIA & rats & $\begin{array}{l}\text { cerebral ischemia } \\
\text { - middle cerebral } \\
\text { artery occlusion } \\
\text { MCAO }\end{array}$ & $\begin{array}{l}\text { biochemical histo- } \\
\text { logical and neuro- } \\
\text { logical examination }\end{array}$ & 20 mg/mL (i. p.) & $\begin{array}{l}\text { reduced neurologic } \\
\text { deficit, brain water con- } \\
\text { tent, and infarct size; } \\
\text { decreased IgG evasion } \\
\text { of brain tissues (BBB } \\
\text { protection) }\end{array}$ & [22] \\
\hline $\begin{array}{l}\text { Tanshinone IIA \& } \\
\text { tanshinone IIB }\end{array}$ & mice & $\begin{array}{l}\text { cerebral ischemia } \\
\text { - middle cerebral } \\
\text { artery occlusion }\end{array}$ & $\begin{array}{l}\text { biochemical histo- } \\
\text { logical and neuro- } \\
\text { logical examination }\end{array}$ & $10 \mathrm{mg} / \mathrm{kg}$ (i. p.) & $\begin{array}{l}\text { reduced infarct size and } \\
\text { brain edema formation }\end{array}$ & [23] \\
\hline Tanshinone IIA & rats & $\begin{array}{l}\text { cerebral ischemia } \\
\text { - middle cerebral } \\
\text { artery occlusion }\end{array}$ & $\begin{array}{l}\text { biochemical } \\
\text { histological exami- } \\
\text { nation }\end{array}$ & 20 mg/kg (i. p.) & $\begin{array}{l}\text { reduced neurological } \\
\text { deficit scores, brain } \\
\text { water content, and } \\
\text { infarct size }\end{array}$ & [24] \\
\hline Tanshinone IIA & rats & $\begin{array}{l}\text { cerebral ischemia } \\
\text { - middle cerebral } \\
\text { artery occlusion }\end{array}$ & $\begin{array}{l}\text { histological } \\
\text { biochemical }\end{array}$ & $\begin{array}{l}10,20 \text { and } 30 \mathrm{mg} / \\
\mathrm{mL} \text { (i. p.) }\end{array}$ & $\begin{array}{l}\text { reduced brain water } \\
\text { content and infarct size, } \\
\text { protected BBB }\end{array}$ & [25] \\
\hline $\begin{array}{l}\text { Tanshinone IIA loaded in } \\
\text { PEGylated albumin nano- } \\
\text { particles }\end{array}$ & rats & $\begin{array}{l}\text { cerebral ischemia } \\
\text { - middle cerebral } \\
\text { artery occlusion }\end{array}$ & $\begin{array}{l}\text { histological } \\
\text { biochemical }\end{array}$ & $\begin{array}{l}\text { TIIA nanoparticles, } \\
10 \mathrm{mg} / \mathrm{kg} \text { (i.v.) }\end{array}$ & $\begin{array}{l}\text { reduced the neuro- } \\
\text { logical dysfunctions, } \\
\text { infarction volume, neu- } \\
\text { trophils infiltration and } \\
\text { neuronal apoptosis }\end{array}$ & {$[26,35]$} \\
\hline Tanshinone IIA & rats & $\begin{array}{l}\text { cerebral ischemia } \\
\text { - middle cerebral } \\
\text { artery occlusion }\end{array}$ & $\begin{array}{l}\text { histological } \\
\text { biochemical }\end{array}$ & 4 and 8 mg/kg (i.p.) & reduced infarct size & [27] \\
\hline Tanshinone IIB & rats & $\begin{array}{l}\text { cerebral ischemia } \\
\text { - middle cerebral } \\
\text { artery occlusion }\end{array}$ & histological & $\begin{array}{l}5 \text { and } 25 \mathrm{mg} / \mathrm{kg} \\
\text { (i. p.) }\end{array}$ & $\begin{array}{l}\text { reduced the focal in- } \\
\text { farct volume, cerebral } \\
\text { histological damage, } \\
\text { and apoptotic cells }\end{array}$ & [36] \\
\hline
\end{tabular}

TSIIA significantly $(\mathrm{p}<0.05)$ repressed COX-2 mRNA expression and effectively suppressed tumor growth and angiogenesis of human colorectal cancer via inhibiting the expression level of COX-2 and VEGF [43].

In addition, TSIIA was able to inhibit in vitro $\mathrm{A} \beta$ formation and disaggregate preformed $A \beta$ fibrils [45]. Lastly, Zhou and coworkers [46] evidenced a potent inhibition of AChE activities in PC- 12 cells in vitro by TSIIA.

The biochemical mechanisms related to TSIIA are summarized in - Table 3.

\section{Tanshinone I}

Pretreatment with TSI had several effects against cerebral I/R injury in the gerbil hippocampus [48]. It increased the immunoreactivities and protein levels of anti-inflammatory cytokines IL4 and IL-13, but did not increase the immunoreactivities and protein levels of proinflammatory cytokines IL-2 and TNF- $\alpha$. Neuroprotection of TSI can be related to the maintenance or the increase of antioxidants (SOD1 and SOD2) and neurotrophic factors (BDNF and IGF-I) in the stratum pyramidale of the hippocampal region CA1.

TSI can inhibit $A \beta$ aggregation, disaggregate $A \beta$ fibers, and reduce $A \beta$-induced cell toxicity in vitro [45]. TSI showed a better inhib- itory potency compared to TSIIA with a preferential bind to a hydrophobic $\beta$-sheet groove formed by the C-terminal residues of Isoleucine 31 , Methionine35, and Valine39 of the $A \beta$ pentamer [45].

Park and coworkers [21] reported that TSI was the best neuroprotective tanshinone in the hippocampal CA1 region, using GFAP and IB4 immunohistochemistry. IB4 immunoreactivities were reduced only in the TSI-treated ischemia group [21].

Kim and coworkers [49] reported that TSI activated ERK-CREB signalling pathways in normal mice and ameliorated memory impairments induced by a $\mathrm{GABA}_{\mathrm{A}}$ receptor agonist or an NMDA receptor antagonist, accompanied by the inhibition of learningassociated ERK and CREB activation in the mouse hippocampus. Furthermore, TSI significantly $(\mathrm{p}<0.05)$ increased CREB phosphorylation (a memory formation marker) in the hippocampus, which suggests that CREB activation by TSI was mediated via ERK phosphorylation. TSI significantly $(\mathrm{p}<0.05)$ prevented the reductions in the phosphorylation of ERK and CREB induced by diazepam [49].

Tung and coworkers [50] proved that TSI was more effective than TSII in inhibiting the growth of lung cancer cells via suppressing the expression of VEGF, cyclin A, and cyclin B proteins in a dosedependent manner. 
Table 2 In vivo studies of the hydrophilic constituents of S. miltiorrhiza.

\begin{tabular}{|c|c|c|c|c|c|c|}
\hline $\begin{array}{l}\text { Type of constituent/ } \\
\text { extract }\end{array}$ & Animals & Model of CNS trauma & $\begin{array}{l}\text { Evaluation of } \\
\text { CNS parameters }\end{array}$ & Treatment & Outcome & $\begin{array}{l}\text { Refer- } \\
\text { ence }\end{array}$ \\
\hline Danshensu & mice & $\begin{array}{l}\text { advanced glycation end } \\
\text { product-mediated neuroin- } \\
\text { flammation-(streptozocin } \\
\text { induced) }\end{array}$ & $\begin{array}{l}\text { Morris water maze } \\
\text { test }\end{array}$ & $\begin{array}{l}15,30 \text {, or } \\
60 \mathrm{mg} / \mathrm{kg} \text { for } \\
12 \text { weeks (ga- } \\
\text { vage) }\end{array}$ & $\begin{array}{l}\text { ameliorated acquisi- } \\
\text { tion and retrieval pro- } \\
\text { cesses }\end{array}$ & [31] \\
\hline $\begin{array}{l}\text { Danshensu sodium } \\
\text { salt }\end{array}$ & rats & $\begin{array}{l}\text { cerebral ischemia - middle } \\
\text { cerebral artery occlusion } \\
\text { (MCAO) }\end{array}$ & $\begin{array}{l}\text { biochemical histo- } \\
\text { logical examina- } \\
\text { tion }\end{array}$ & $\begin{array}{l}30 \mathrm{mg} / \mathrm{kg} \text { and } \\
60 \mathrm{mg} / \mathrm{kg} \\
\text { (i. v.) }\end{array}$ & $\begin{array}{l}\text { improved neurologic } \\
\text { deficits and survival } \\
\text { rate, reduced infarct } \\
\text { volume and number } \\
\text { of dead neurons }\end{array}$ & [28] \\
\hline Caffeic acid dimer & rats & $\begin{array}{l}\text { cerebral ischemia - middle } \\
\text { cerebral artery occlusion } \\
\text { (MCAO) }\end{array}$ & $\begin{array}{l}\text { biochemical histo- } \\
\text { logical examina- } \\
\text { tion }\end{array}$ & $\begin{array}{l}25 \mathrm{mg} / \mathrm{kg} \\
\text { (i.v.) }\end{array}$ & $\begin{array}{l}\text { ameliorated brain } \\
\text { mitochondrial struc- } \\
\text { ture and function }\end{array}$ & [29] \\
\hline $\begin{array}{l}\text { Salvianolic acid B } \\
\text { magnesium salt }\end{array}$ & rats & $\begin{array}{l}\text { cerebral ischemia - middle } \\
\text { cerebral artery occlusion } \\
\text { (MCAO) }\end{array}$ & $\begin{array}{l}\text { biochemical histo- } \\
\text { logical examina- } \\
\text { tion }\end{array}$ & $\begin{array}{l}15,30 \text { and } \\
60 \mathrm{mg} / \mathrm{kg} \\
\text { (i. v.) }\end{array}$ & $\begin{array}{l}\text { decreased brain water } \\
\text { content, glutamate } \\
\text { levels, and cerebral } \\
\text { infarct zones }\end{array}$ & {$[30]$} \\
\hline Salvianolic acid B & $\begin{array}{l}\text { male CD1 mice/ } \\
\text { pregnant } \\
\text { Sprague-Dawley } \\
\text { rats }\end{array}$ & $\begin{array}{l}\text { scopolamine, diazepam, } \\
\text { muscimol, or } A \beta_{(25-35)} \text { pep- } \\
\text { tide injection }\end{array}$ & $\begin{array}{l}\text { passive avoidance } \\
\text { Y-maze, Morris } \\
\text { water maze }\end{array}$ & $\begin{array}{l}10 \mathrm{mg} / \mathrm{kg} \text { for } \\
7 \text { weeks (os) }\end{array}$ & $\begin{array}{l}\text { reversed the cognitive } \\
\text { impairments induced } \\
\text { by scopolamine or } \\
A \beta_{(25-35)} \text { injection }\end{array}$ & [32] \\
\hline Salvianolic acid B & mice & $\begin{array}{l}\text { amyloid peptide (Ab)-in- } \\
\text { duced Alzheimer's disease }\end{array}$ & passive avoidance & $\begin{array}{l}10 \mathrm{mg} / \mathrm{kg}, 7 \\
\text { days (os) }\end{array}$ & $\begin{array}{l}\text { improved memory } \\
\text { impairment }\end{array}$ & [33] \\
\hline Salvianolic acid B & rats & $\begin{array}{l}\text { cognitive dysfunction } \\
\text { caused by high-fat diets }\end{array}$ & Morris water maze & $\begin{array}{l}14 \mathrm{mg} / \mathrm{kg} \text { for } \\
7 \text { weeks (os) }\end{array}$ & $\begin{array}{l}\text { dyslipidemia and } \\
\text { cognitive deficits } \\
\text { were reversed }\end{array}$ & [34] \\
\hline
\end{tabular}

Table 3 Biochemical mechanisms of TSIIA.

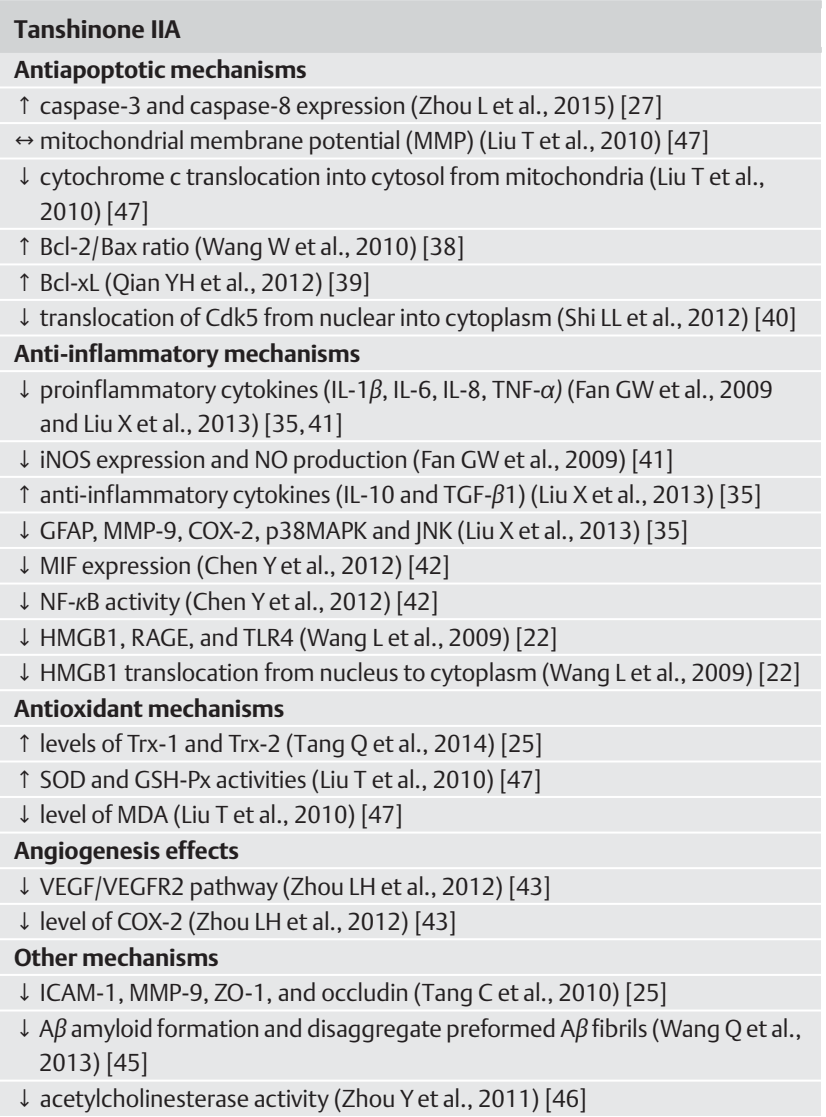

Finally, Zhou and coworkers [46] reported that TSI also had a potent AChE inhibitory activity, suggesting that the aromatic A ring was essential for such inhibition.

The biochemical mechanisms related to TSI are summarized in o Table 4.

\section{Cryptotanshinone}

CTS modulated the APP metabolism by elevating $\alpha$-secretase activity and SAPP $\alpha$ release [50]. CTS is able to protect H9c2 cells against apoptosis induced by chronic hypoxia via acting on the mitochondrial apoptosis signalling pathway [52]. CTS can prevent chronic hypoxia by targeting the mitochondrial death pathway via balancing in anti- and proapoptotic proteins in the Bcl-2 family proteins, and by inhibitioning of mitochondria membrane hyperpolarization, cytochrome $\mathrm{c}$ translocation, caspase 3 activity, and inactivation of the HIF- $1 \alpha$ protein [53].

The biochemical mechanisms related to CTS are summarized in - Table 5.

\section{Effects of depsides}

In recent years, much attention has been directed to the watersoluble components that represent the major constituents of $S$. miltiorrhiza decoction used in traditional medicine. Studies are mainly carried out with the principal constituents SalB, SalA, DSS, and RA.

\section{Salvianolic acid B}

In the study of Zhou and coworkers [46], SalB was tested as a blocking agent of $\mathrm{A} \beta$-induced $\mathrm{Ca}^{2+}$ intake in PC-12 cells. This study showed that $15 \mu \mathrm{M} \mathrm{A} \beta_{25-35}$ caused about $40 \%$ additional LDH release from $A \beta$-treated cells compared with normal cells, and the cotreatment with SalB inhibited the LDH release from $\mathrm{A} \beta$-treated cells. 
Table 4 Biochemical mechanisms of TSI.

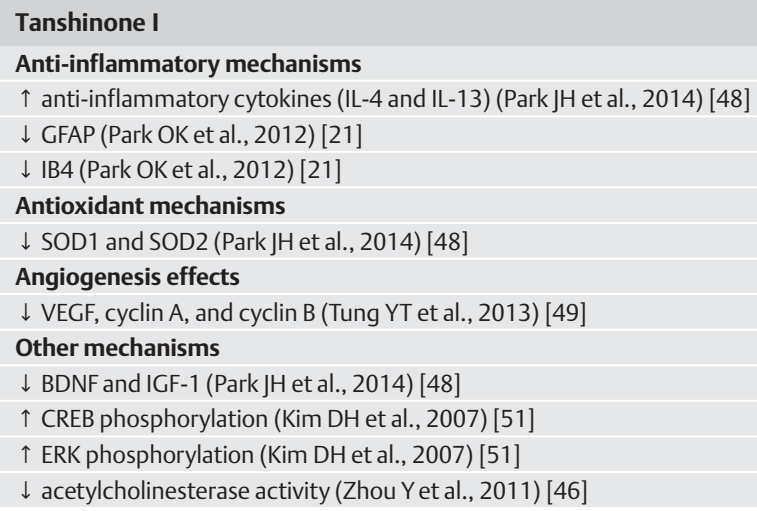

Table 5 Biochemical mechanisms of CTS.

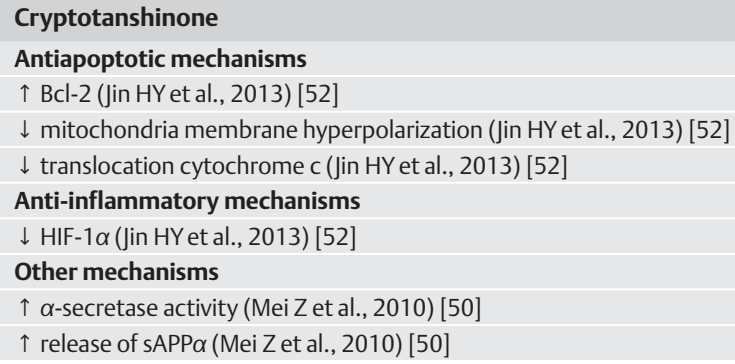

Table 6 Biochemical mechanisms of SalB.

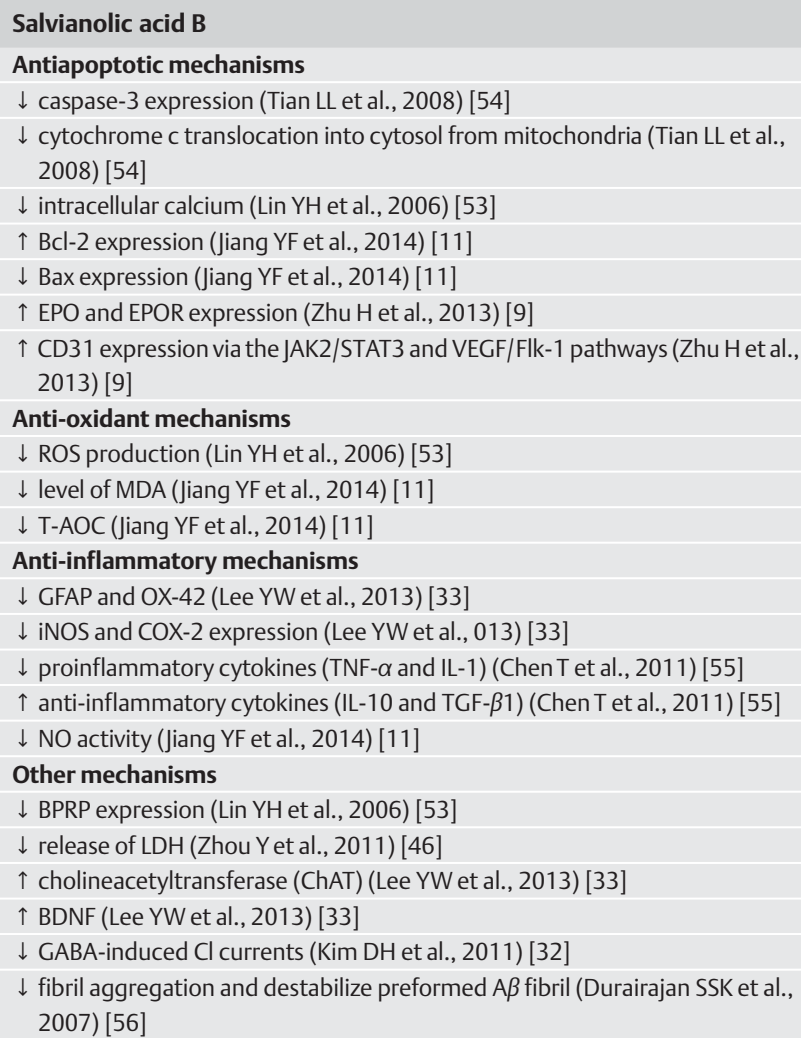

Lin and coworkers [53] investigated the neuroprotective effects of SalB on the expression of BPRP. Treatment of the PC12 cells with SalB significantly $(\mathrm{p}<0.05)$ reversed the expression of BPRP and cell viability while it decreased ROS production and intracellular calcium.

In a further study [33] of rats pretreated with $10 \mathrm{mg} / \mathrm{kg}$ SalB, the number of GFAP and OX-42 positive cells were reduced. Furthermore, subchronic SalB administration decreased iNOS and COX-2 expression. The subchronic SalB administration decreased choline acetyltransferase expression levels by enhancing BDNF protein levels [33].

Tian and coworkers [54] investigated the neuroprotective effects of SalB against 6-hydroxydopamine-induced cell death in human neuroblastoma SH-SY5Y cells. SalB significantly $(p<0.05)$ reduced the 6-hydroxydopamine-induced generation of ROS and prevented 6-hydroxydopamine-induced increases in intracellular calcium. The data demonstrated that SalB reduced the 6-hydroxydopamine-induced increase of caspase-3 activity, and reduced cytochrome $\mathrm{C}$ translocation into cytosol from mitochondria [55].

Chen and coworkers [55] investigated the protective effects of SalB in traumatic brain injury in mice. SalB treatment markedly suppressed the expression of proinflammatory cytokines TNF- $\alpha$ and IL- $1 \beta$, and enhanced the expression of anti-inflammatory cytokines IL-10 and TGF- $\beta 1$ after traumatic brain injury.

More recently, Jiang and coworkers [11] examined the effects of SalB in a mouse model of cerebral ischemia and reperfusion injury with sodium nitroprusside. Pretreatment with SalB decrease the MDA content and NOS activity, and increased the T-AOC level in the cortical area of $I / R$. SalB also improved pathological changes of hippocampal CA1 neurons by preventing neuronal loss, increasing $\mathrm{Bcl}-2$ protein expression, inhibiting Bax protein expression, and enhancing the ratio of Bcl-2-IR to Bax-IR.

In the study of Kim and coworkers [32], it was observed that SalB ameliorated the memory impairments induced by scopolamine or the $A \beta_{25-35}$ peptide. SalB can inhibit GABA-induced $\cdot \mathrm{Cl}^{-}$currents in a single hippocampal neuron in a concentration-dependent manner. Therefore, the scopolamine-induced amnesic animal model might be the result of the inhibition of GABA signalling [32].

In addition, SMND-309, a derivative of SalB, increased the survival of neurons and promoted angiogenesis by enhancing EPO and EPOR expression, which subsequently increase CD31 expression via the JAK2/STAT3 and VEGF/Flk-1 pathways [9].

Durairajan and coworkers [56] showed that SalB could inhibit fibril aggregation as well as destabilize preformed $A \beta$ fibril in a dose- and time-dependent manner. SalB might interact with the peptide side chain to inactivate fibril aggregation.

The biochemical mechanisms related to SalB are summarized in - Table 6.

\section{Salvianolic acid $A$}

Cao and coworkers [12] proved that SalA (50-100 $\mu \mathrm{M})$ inhibits $A \beta_{42}$ self-mediated aggregation and disaggregates $A \beta_{42}$ aging fibrils in a dose-dependent manner.

Wang and coworkers [57] demonstrated that SalA protects SHSY5Y cells against $\mathrm{MPP}^{+}$-induced cytotoxicity. SalA ameliorates $\mathrm{MPP}^{+}$-induced ROS production, increases the number of viable cells, inhibits apoptotic pathways, prevents caspase-3 activation, and decreases the number of apoptotic cells.

In another study [58], SalA was able to activate Nrf2, inducing HO-1 expression and protecting against oxidative stress in RPE 
Table 7 Biochemical mechanisms of SalA.

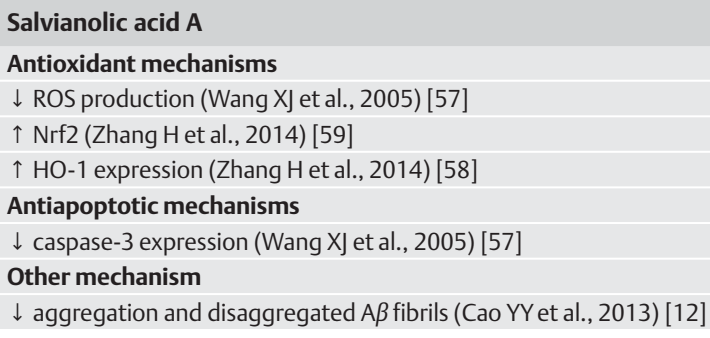

Table 8 Biochemical mechanisms of DSS.

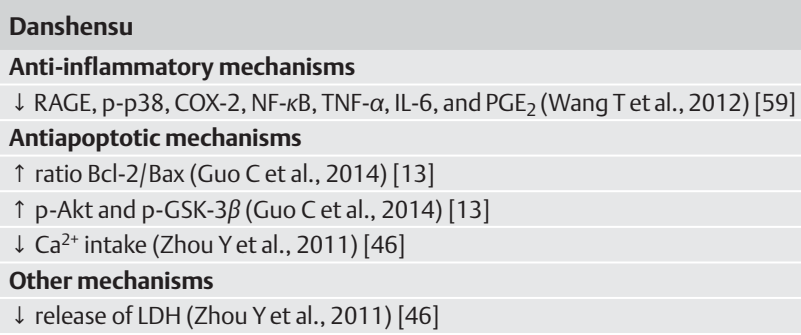

Table 9 Biochemical mechanisms of RA.

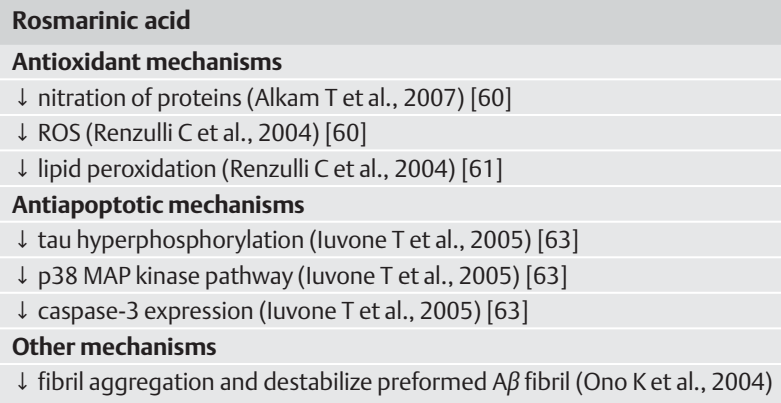

cells by activating the Akt/mammalian target of rapamycin signalling. SalA induced Nrf2 phosphorylation through a mechanism dependent on PI3 K/Akt/mTORC1 activation. The transcription factor Nrf2 plays a vital role in ARE-mediated expression of phase II detoxifying and antioxidant enzymes, as well as in the prevention of cell damage caused by oxidative stress. Akt-dependent mTORC1 signalling might be responsible for Nrf2 activation, as rapamycin blocked SalA-induced Nrf2 phosphorylation and nuclear translation, as well as HO-1 induction [58].

The biochemical mechanisms related to SalA are summarized in Table 7.

\section{Danshensu}

DSS blocked the expression of RAGE, p-p38, and COX-2, and NF$\kappa \mathrm{B}$ activation, and inhibited the increase of TNF- $\alpha$, IL- 6 , and PGE 2 [59]. It is known that AGEs bind to RAGE, transmitting the signal from RAGE to NF- $k$ B-regulated cytokines. DSS did not change the expression of AGEs but blocked the increased expression of RAGE [59]. Therefore, it may reduce not only the production of ROS, but also it could result in the reduction of $\mathrm{p} 38$ phosphorylation lead- ing to the decrease of NF- $k$ B activation, in turn, downregulating the inflammatory response in the hippocampus. Sodium DSS amplified the ratio of $\mathrm{Bcl}-2 / \mathrm{Bax}$ and the levels of p-Akt and p-GSK$3 \beta$ [13]. Phosphorylation of Akt promotes cell survival against cerebral ischemic injury by phosphorylation and subsequent inactivation of many proapoptotic proteins, such as GSK-3 $\beta$, procaspase-9, and forehead transcription factor (FKHR) [13].

In addition, DSS could protect PC- 12 cells from $\mathrm{A} \beta$-induced cytotoxicity by improving cell viability, inhibiting $\mathrm{Ca}^{2+}$ intake, and reducing $\mathrm{LDH}$ release [46].

The biochemical mechanisms related to DSS are summarized in - Table 8.

\section{Rosmarinic acid}

The study of Alkam and coworkers [60] examined the protective effects of RA on memory impairment in a mouse model induced by acute intracranial injection of $A \beta_{25-35}$. RA prevented $A \beta_{25-35^{-}}$ induced nitration of proteins and impairment of recognition memory [60].

Renzulli and coworkers [61] clarified that that RA reduces, in a concentration-dependent manner, $A \beta_{42}$-induced ROS formation and lipid peroxidation.

Interestingly, Ono and coworkers [62] reported that RA inhibited the formation of fibrils from $A \beta$ and destabilized preformed $A \beta$ fibrils in vitro.

Furthermore, Iuvone and coworkers [63] demonstrated that RA is able to inhibit tau hyperphosphorylation, probably through the inhibition of the p38 MAP kinase pathway but not via the inhibition of GSK-3 hyperphosphorylation. RA inhibited caspase-3 activation and DNA fragmentation, thus suggesting that RA could affect the execution phase of $A \beta$-induced apoptosis [63].

The biochemical mechanisms related to RA are summarized in - Table 9.

\section{Complementary Biochemical Mechanisms of Tanshinones and Depsides on Central Nervous System Neuronal Injury and Degeneration $\nabla$}

Briefly, the principal established mechanisms for both classes of constituents are summarized in $\odot$ Fig. $\mathbf{3}$.

Both tanshinones and depsides are $A \beta$ inhibitors but their mechanisms are complementary due to their different structure, the lipophilic tanshinones, and the hydrophilic depsides.

TSAII and TSI contain an aromatic ring structure similar to other typical organic $A \beta$ inhibitors and it is likely that tanshinones interact with aromatic residues of $A \beta$ to form a $\pi-\pi$ stacking arrangement between tanshinone and $A \beta$. TSAII and TSI have a comparable ability to disassemble the existing $A \beta$ fibrils, although TSI showed a better inhibitory potency to prevent $A \beta$. Both TSAII and TSI prefer to bind to the C-terminal $\beta$-sheet, particularly hydrophobic residues $\mathrm{I31}, \mathrm{M} 35$, and V39 of the $\mathrm{A} \beta$ pentamer. These binding sites interfere with the lateral association of $\mathrm{A} \beta$ oligomers into higher-order aggregates.

By contrast, depsides inhibit the aggregation of $A \beta$ by stabilizing the $\alpha$-helix structure at A $\beta$ 's C-terminus and by preventing the transformation process from $\alpha$-helix to $\beta$-sheet. Initially, depsides bind to $\mathrm{A} \beta$ at its $\mathrm{C}$-terminus, and forms three hydrogen bonds at residues Lys16 and Asp23. Then depsides are more deeply docked in the pocket of the helix and C-terminus. This complex of depsides- $A \beta$ is energetically more stable [12]. 


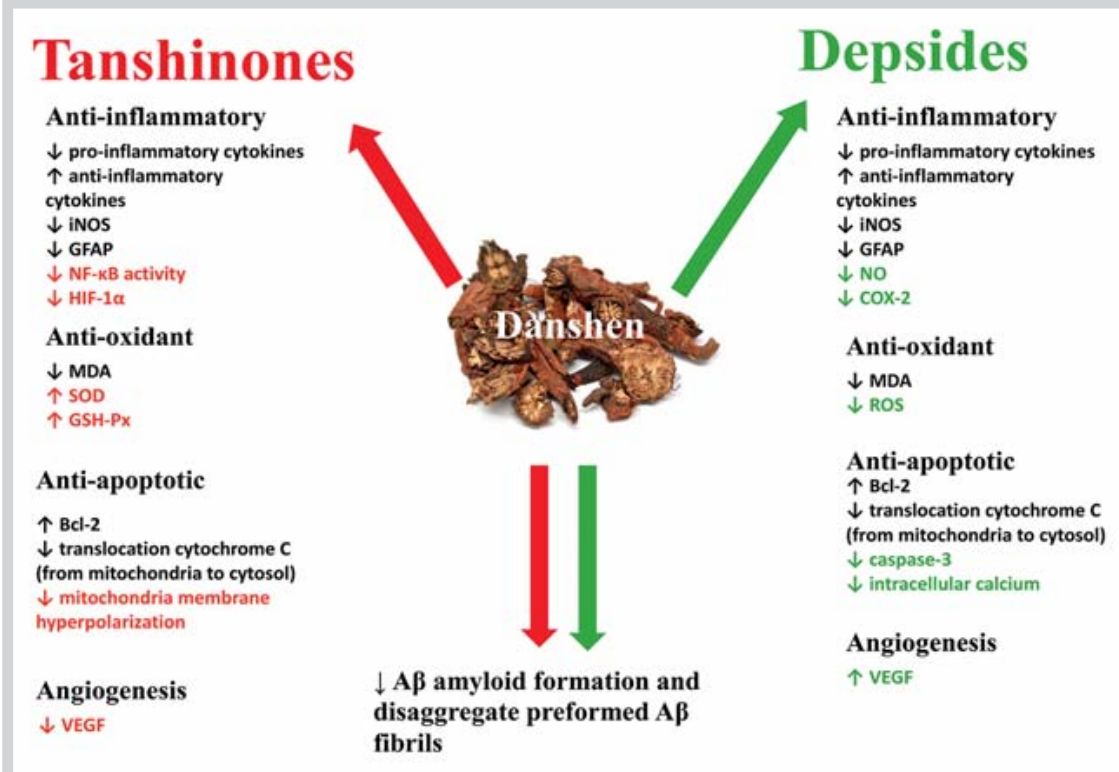

Fig. 3 Biochemical mechanisms of tanshinones and depsides against CNS neuronal injury and degeneration. (Color figure available online only).

Inhibitors of AChE

Additionally, considerable data suggest that inflammation contributes to many CNS diseases, and therefore represents a plausible therapeutic target for intervention. A wealth of potential inflammatory targets for intervention have been proposed, including microglial activation and leukocyte extravasation via adhesion molecules or MMPs, NO and iNOS, COX-2, and cytokines such as IL-1 and TNF $\alpha$ [64].

A number of anti-inflammatory mechanisms have been reported for both tanshinones and depsides, and they can be beneficial in many CNS disorders. Common mechanisms are the effects on cytokines, iNOS, and GFAP. The release of proinflammatory cytokines represents the first stage of acute CNS diseases and many chronic pathologies, such as multiple sclerosis.

Increased iNOS expression contributes to many CNS diseases, and inhibitors have been explored as potential targets for intervention, while GFAP is considered an important biomarker for astroglial pathology in neurological diseases providing a background to protein synthesis, assembly, function, and degeneration.

In addition, depsides are inhibitors of NO and COX2. COX exists as two major isozymes: COX-1 is expressed constitutively in many tissues with a role in normal homeostasis, whereas COX-2 is induced in response to inflammatory mediators. Increases in COX2 activity have been associated with ischemic damage in experimental strokes and COX-2 is induced in areas with evidence of recent demyelination. Consequently, COX-2 inhibitors protect neuronal cells from amyloid toxicity in vitro, and promote neuronal survival in animal models of ischemic and excytotoxic neurodegeneration. COX-2 inhibitors also reduced neuronal damage in the experimental model of Parkinson's disease.

NO can exert both protective and deleterious actions in ischemic events. Initially, NO produced by endothelial NOS is protective through its vasodilatory action, but subsequently, NO produced via neuronal NOS and iNOS contributes to ischemic damage.

Modulation of NO levels has been reported not only in the neurons of the CNS, but also in the glial cells (microglia and astroglia) activated during the neuroinflammatory response. Thus, NO and the pathways triggering its release are emerging as an important research focus in the search for strategies to prevent, halt, or cure neurodegenerative diseases.

By contrast, tanshinones inhibit HIF- $\alpha$ and NF- $k$ B. HIF- $\alpha$ is the alpha subunit of the hypoxia-inducible factor, which is an important transcription factor that regulates cellular metabolism and survival under hypoxic stress. HIFs regulate cellular stress responses in tandem with NF- $k$ B to control hypoxic inflammation through the activation of cytokine and hypoxia pathways. HIF can be activated in response to multiple stimuli, such as bacterial lipopolysaccharides, microtubule disruption, IL-18 and TNF- $\alpha$, hepatocyte growth factor, and ROS [64].

It is well documented that oxidative stress has been implicated as one of the leading causes for brain damage induced by cerebral I/ R. Compared to other tissues in the body, the brain is particularly vulnerable to oxidative damage because of the high oxygen consumption rate and metabolic rate. In addition, the relatively lower antioxidative capacities, such as low to moderate activities of SOD, catalase, and GSH-Px, make the brain a target for free radical attack. There is evidence that GSH plays an important role in the detoxification of ROS in the brain, which is secreted primarily by macrophages. Again, the different mechanisms described for tanshinones and depsides can be complementary in the protection of CNS from oxidative stress [65].

Neuronal death underlies the symptoms of many human neurological disorders, including AD, Parkinson's, and Huntington's disease, stroke, and amyotrophic lateral sclerosis. During the initiation phase of apoptosis, the death signal activates an intracellular cascade of events that may involve increases in the levels of oxyradicals and $\mathrm{Ca}^{2+}$, production of Par-4, and translocation of proapoptotic Bcl-2 family members (Bax and Bad) to the mitochondrial membrane. Certain caspases (caspase-8, for example) can also act early in the cell death process before, or independently of, mitochondrial changes. The effector phase of apoptosis involves increased mitochondrial $\mathrm{Ca}^{2+}$ and oxyradical levels, the formation of permeability transition pores in the mitochondrial membrane, and the release of cytochrome $\mathrm{c}$ into the cytosol. Cytochrome $\mathrm{c}$ forms a complex with apoptotic protease-activating factor 1 and caspase-9. Activated caspase-9, in turn, activates cas- 
pase-3, which begins the degradation phase of apoptosis in which various caspases and other enzyme substrates are cleaved, resulting in characteristic changes in the plasma membrane [66]. Once more, different and complementary roles are reported by tanshinones and depsides as reported in 0 Fig. 3.

Remarkably, both classes of constituents have a VEGF effect but it is divergent; depsides enhance VEGF production, while tanshinones decrease VEGF expression. VEGF is considered specific for endothelial cells, but it also has effects on neurons and glia in a number of ways. VEGF enhances neuronal proliferation, neurite outgrowth and maturation, and neuronal survival. A neuroprotective role for VEGF is supported by the demonstration that VEGF reduces excytotoxic damage to cultured hippocampal neurons and reduces damage in vivo after ischemia. Together with the evidence that VEGF expression increases after ischemia, traumatic brain injury, and seizures, it is possible that VEGF is an endogenous neuroprotective agent in the CNS. However, despite the potential importance of VEGF as a neuroprotective growth factor, few direct studies of VEGF on neurons or glia have been published to clarify its actions [67]. Astonishing, VEGF also demonstrated a remarkable potency in the epileptic brain, as a consequence, VEGF or VEGF-related targets could provide useful endpoints to direct novel therapeutic strategies for epilepsy [67].

Finally, tanshinones are inhibitors of AChE, suggesting possible important rules in Parkinson's disease but also beneficial advances in pharmacotherapy of disorders such as schizophrenia and AD [68].

The inhibitory activities of tashinones were evaluated using physostigmine as a standard drug ( $\mathrm{IC}_{50}$ was $\left.2.5 \times 10^{-7} \mathrm{M}\right)$. DTSI and CTS were the most potent inhibitors $\left(\mathrm{IC}_{50} \mathrm{~s}\right.$ were $1.0 \times 10^{-6} \mathrm{M}$ and $7 \times 10^{-6} \mathrm{M}$, respectively). TSI and TSIIA had only weak inhibitory effects.

The structures of DTSI have a much greater activity than TSI, which differs by only one double bond, as DTSI has a dihydrofuran ring while TSI has a furan ring. CTS and TSIIA show a similar difference in activity, so it appears that the dihydrofuran ring is crucial for AChE inhibitory activity. CTS has a sevenfold higher activity than DTSI, which suggests that an aromatic A ring may contribute more to inhibitory activity than a hexane A ring. Additionally, the clogP values of DTSI, CTS, TSI, and TSIIA were calculated as $2.4,3.4,4.8$, and 5.8 , respectively, which indicates that these compounds have the potential to penetrate the BBB, but their lipophilicity is inversely related to the cholinesterase inhibitory activity [46].

These results also support the traditional application of this plant to alleviate cognitive dysfunction and could serve as an interesting template for the development of new drugs against AD.

\section{Pharmacokinetics Figures and Biodistribution of Salvia miltiorrhiza Constituents}

$\nabla$

Pharmacokinetic and biodistribution studies are very limited, generally related to single isolated constituents, rarely report biodistribution to the brain, and most of them only evaluate the plasmatic concentration of administered constituents or their metabolites. Studies related to lipophilic compounds are mainly concerning formulations developed with the aim to improve their bioavailability.

A unique trial on humans, a randomized, open-label, single-dose study, was conducted in 12 healthy Chinese [ 6 males, 6 females; mean age $25.2(3.8 \pm S D)$ years] volunteers receiving a single in- travenous infusion of a 100- or 200-mg mixture of depside salts (SalB ca. $88 \%$, RA ca. $4.5 \%$, and LA LSB ca. $1 \%$ ), a multicomponent drug marketed in China for the treatment of coronary heart disease [69]. Peak plasma concentrations of depsides were observed at 0.3 to $1 \mathrm{~h}$ following the $1-\mathrm{h}$ i.v. infusion. Peak plasma concentrations of SalB had mean concentrations of $4925 \mathrm{ng} / \mathrm{mL}$ at the 100 -mg dose and $10285 \mathrm{ng} / \mathrm{mL}$ at the $200-\mathrm{mg}$ dose. Immediately after $C_{\max }$, there was a rapid decline in the plasma concentrations. The mean $C_{\max }$ values for RA and LA were between 150$400 \mathrm{ng} / \mathrm{mL}$, according to the different dosages. No significant difference in pharmacokinetic parameters was observed between male and female subjects. RA was eliminated more rapidly than SalB and LA, with the plasma concentration decreasing to less than the lower limit of quantitation within $3 \mathrm{~h}$ of dosing. The $\mathrm{AUC}_{\text {last }}$ value of LSB was much greater than those of RA and LA, which is in agreement with the high amount of SalB (ca. 88\%). According to these results, SalB is methylated rapidly in the liver and most of the metabolites (M1, M2, and M3 detected in the plasma with very low concentrations between 50 and $170 \mathrm{ng} /$ $\mathrm{mL}$ ) are excreted directly into bile and finally into feces. The low urinary excretion of LSB $(0.58 \%)$ also indicated that renal secretion is not the main excretion pathway [69].

An interesting study was conducted with the aim to evaluate the pharmacokinetic interaction between tanshinones and depsides [70]. Rats were administered i.v. with an emulsion of $10 \mathrm{mg} / \mathrm{kg}$ tanshinone extract (equivalent to $4.0 \mathrm{mg} / \mathrm{kg}$ TSIIA), $100 \mathrm{mg} / \mathrm{kg}$ depside extract solution (equivalent to $61.2 \mathrm{mg} / \mathrm{kg} \mathrm{SalB}$ ), or a mixed extract-loaded emulsion (equivalent to $4.0 \mathrm{mg} / \mathrm{kg}$ TSIIA and $61.2 \mathrm{mg} / \mathrm{kg}$ SalB). The AUCs of both TSIIA and SalB were considerably increased (about 2- to 14-fold) after i.v. administration of the mixed extract-loaded emulsion in comparison with the equivalent dose of the corresponding extract administration. The $C_{\max }$ concentrations of TSIIA and SalB were also both significantly increased $(p<0.01)$. However, no significant differences in the $t_{1 / 2}$ of TSIIA and SalB in the mixed extract-loaded emulsion groups were found compared with that of the corresponding extract groups, except for the high dose groups of TSIIA $(p<0.05)$. Therefore, a pharmacokinetic interaction occurs between tanshinones and depsides after i.v. administration in rats, which affects the pharmacokinetic process of TSIIA and SalB in vivo [70].

To the best of our knowledge, only one study estimated the pharmacokinetics of depsides in the rat blood and brain by microdialysis sampling [71]. A mixture of depsides (DSS $40 \mathrm{mg} / \mathrm{kg}$ BW, protocatechuic aldehyde $149 \mathrm{mg} / \mathrm{kg}$ BW, and SalB $50 \mathrm{mg} / \mathrm{kg}$ BW) was administrated intragastrically, and then blood and brain microdialysates were collected at 15- and 30-min time intervals for $4 \mathrm{~h}$, respectively. DSS and protocatechuic acid were detected in both blood and brain microdialysates, while protocatechuic aldehyde and SalB were not detected. Brain-to-blood (AUC $C_{\text {brain }} /$ $\mathrm{AUC}_{\text {blood }}$ ) distribution ratios were $0.25 \pm 0.04$ and $0.09 \pm 0.02$ for DSS and protocatechuic acid, respectively [71]. DSS can readily permeate the BBB after oral administration of the total extract, and protocatechuic acid is a potential metabolite of protocatechuic aldehyde.

Several other studies in animals concerning depsides after oral or i. v. administration have been reported in the literature. They all concluded that depsides after oral administration are characterized as having rapid oral absorption, quick clearance, and poor absolute bioavailability; after i.v. administration, they were extensively metabolized and degraded rapidly.

A study was carried out after the single-dose oral administration of SalA (5, 10, and $20 \mathrm{mg} / \mathrm{kg}$ doses) in beagle dogs. The lack of 
dose proportionality over the dose range, with an absolute bioavailability from $1.47 \%$ to $1.84 \%$ [ 72 ], is noteworthy.

Additionally, Hou and coworkers [73] evaluated the plasma concentrations of SalA after a single i.v. administration of $5 \mathrm{~mL} / \mathrm{kg}$ of an $S$. miltiorrhiza injection to male Sprague-Dawley rats. The following data were found: $\mathrm{t}_{1 / 2} \alpha$ was $0.139 \pm 0.035 \mathrm{~h}, \mathrm{t}_{1 / 2} \beta$ was $1.346 \pm 0.307 \mathrm{~h}$, AUC $(0-4 \mathrm{~h})$ was $25.142 \pm 6.858 \mathrm{mg} \cdot \mathrm{h} / \mathrm{L}$, AUC $(0-\propto)$ was $38.014 \pm 8.219 \mathrm{mg} \cdot \mathrm{h} / \mathrm{L}$, CL was $0.105 \pm 0.022 \mathrm{~L} \cdot \mathrm{kg} / \mathrm{h}$, and MRT was $1.145 \pm 0.391 \mathrm{~h}$ [73].

Another study [74] was carried out with LA in rats. The oral bioavailability was $1.15 \%$, with AUC (0-t) values of 301.89 and $3.46 \mathrm{mg} \cdot \mathrm{h} / \mathrm{L}$ after i.v. and oral administration, respectively. The total recovery from bile was $75.36 \%$ ( $0.46 \%$ for LA, $17.23 \%$ for a not described Metabolite 1, and 57.67\% for a not described Metabolite 2) after i.v. administration, and $4.26 \%$ (0.00\% for LA, $0.10 \%$ for Metabolite 1 , and $4.16 \%$ for Metabolite 2 ) after oral administration [74].

A further study [75] was carried out with magnesium salt of SalB at 3, 6, and $12 \mathrm{mg} / \mathrm{kg}$ after i.v. administration in beagle dogs. SalB was distributed and eliminated quickly from the central compartment. The mean $t_{1 / 2} \alpha$ values at doses of $3,6,12 \mathrm{mg} / \mathrm{kg}$ were $2.2,2.7$, and $2.9 \mathrm{~min}$, respectively, and the mean $\mathrm{t}_{1 / 2} \beta$ values were 43,42 , and $42 \mathrm{~min}$, respectively [75].

Additionally, a study with SalB [76] at a dose of $100 \mathrm{mg} / \mathrm{kg}$ SalB administered via the femoral vein gave the following blood parameters: $\mathrm{t}_{1 / 2} \beta$ was $53 \pm 15 \mathrm{~min}$, AUC was $1340 \pm 167 \mathrm{~min} \mu \mathrm{g} / \mathrm{mL}$, $\mathrm{Cl}$ was $79 \pm 9 \mathrm{~mL} / \mathrm{kg} / \mathrm{min}, \mathrm{C}_{\max }$ was $85.2 \pm 12.7 \mu \mathrm{g} / \mathrm{mL}, \mathrm{t}_{\max }$ was $30 \pm 0 \mathrm{~min}$. For bile, the $t_{1 / 2} \beta$ was $9 \pm 1 \mathrm{~min}$ and the AUC was $2080 \pm 278 \mathrm{~min} \mu \mathrm{g} / \mathrm{mL}$. The bile-to-blood distribution $\mathrm{AUC}_{\text {bile/ }}$ $\mathrm{AUC}_{\text {blood }}$ was $1.55 \pm 0.21$ [76].

Concerning the pharmacokinetic of tashinones, there are several studies available in the literature on single tanshinones showing that CTS was metabolized to a major metabolite, TSIIA, and trace amounts of several hydroxyl- and dihydroxyl-CTS derivatives in rats [77-80]. Some showed that TSIIA was metabolized to TSIIB, and some hydroxylated derivatives, dehydrotanshinone IIA and tanshinaldehyde in rats $[77,80,81]$. It was also shown that DTSI was metabolized to TSI by dehydrogenation, hydroxyl derivatives, and a derivative by D-ring hydrolysis in rats [80].

A study was carried out using a commercial standardized fraction of tashinones (equivalent to $1.15 \mathrm{mg} / \mathrm{kg}$ of TSI, $1.10 \mathrm{mg} / \mathrm{kg}$ of DTSI, $4.1 \mathrm{mg} / \mathrm{kg}$ of TSIIA, and $1.91 \mathrm{mg} / \mathrm{kg}$ of CTS) to rats. After oral administration of $10 \mathrm{mg} / \mathrm{kg}$, the $C_{\max }, t_{\max }$, AUC, and $t_{1 / 2}$ were calculated for the different constituents. For TSI, the parameters were $1.63 \pm 0.78 \mathrm{ng} / \mathrm{mL}, 0.42 \pm 0.26 \mathrm{~h}, 3.85 \pm 1.65 \mathrm{ng} \cdot \mathrm{h} / \mathrm{mL}$ and $3.00 \pm 0.32 \mathrm{~h}$, respectively. For DTSI, the values were $3.23 \pm$ $1.40 \mathrm{ng} / \mathrm{mL}, 0.79 \pm 0.19 \mathrm{~h}, 10.2 \pm 3.90 \mathrm{ng} \cdot \mathrm{h} / \mathrm{mL}$, and $1.69 \pm 0.29 \mathrm{~h}$, respectively. The $C_{\max }, t_{\max }$, AUC, and $t_{1 / 2}$ of TSIIA were $2.78 \pm$ $0.96 \mathrm{ng} / \mathrm{mL}, 0.54 \pm 0.25 \mathrm{~h}, 4.53 \pm 0.77 \mathrm{ng} \cdot \mathrm{h} / \mathrm{mL}$, and $2.07 \pm 0.57 \mathrm{~h}$, respectively, while for CTS, they were $0.66 \pm 0.27 \mathrm{ng} / \mathrm{mL}, 0.42 \pm$ $0.20 \mathrm{~h}, 1.09 \pm 0.40 \mathrm{ng} \cdot \mathrm{h} / \mathrm{mL}$, and $1.13 \pm 0.38 \mathrm{~h}$, respectively [82]

All these studies focused on an improvement of the solubility and dissolution rate of tanshinones. Four studies concerning tanshinones in the form of solid dispersion were carried out. A first investigation [83] evaluated the pharmacokinetic plasma profile of a solid dispersion of TSIIA with PEG6000 after a single i.v. or oral dose. TSIIA after a single i.v dose of $2 \mathrm{mg} / \mathrm{kg}$ exhibited a triexponential pattern consisting of rapid distribution $\left(t_{1 / 2} \alpha, 0.024 \mathrm{~h}\right)$, slow redistribution $\left(t_{1 / 2} \beta, 0.34 \mathrm{~h}\right)$, and a terminal elimination phase $\left(t_{1 / 2} \gamma, 7.5 \mathrm{~h}\right)$. TSIIA preferentially distributed into the reticuloendothelial system, especially into the liver and lungs, after either i.v. or oral doses. TSIIA (99.2\%) bound highly to plasma pro- teins, among which lipoprotein played an important role (77.5\%). After single oral administrations of 7, 21, and $63 \mathrm{mg} / \mathrm{kg}$ of TSIIA, the absorption was extremely poor with an absolute bioavailability below $3.5 \%$. Absorptive saturation was deduced from the fact that the AUC and $\mathrm{C}_{\max }$ increased less proportionally to the dose, and the $t_{\max }$ was significantly prolonged. In conclusion, TSIIA has a suitable pharmacokinetic behavior except for its poor absorption due to the low solubility and poor membrane permeability [83].

A second study [84] evaluated the pharmacokinetic figures of CPT, TSI and TSIIA after the administration of a solid dispersion with poloxamer 407 of a special extract of S. miltiorrhiza containing ca. $2.50 \%$ CTS, $1.25 \%$ TSI and $4.60 \%$ TSIIA. Water solubility of CTS, TSI and TSIIA in the dispersion was increased ca. 59-, 20-, and 148 -folds. The in vivo bioavailability of CTS was also increased by solid dispersion formulation, at least 2.5 -fold compared with that of the control group [84].

In a further study, TSIIA was formulated in a ternary solid dispersion pellets with the combination of polyvinylpyrrolidone and poloxamer 188 as dispersing carriers. The formulation remarkably promote the dissolution rate of TSIIA from $60 \%$ to $100 \%$ after $60 \mathrm{~min}$. The in vivo test showed that the $\mathrm{AUC}_{0-\mathrm{t}}$ and $\mathrm{C}_{\max }$ were increased 5.40 and 8.97 times more than that of TSIIA. $\mathrm{T}_{\max }$ value was shortened $(3.80 \pm 0.398) \mathrm{h}$, compared to TSIIA with (5.52 \pm 0.738) h [85].

Moreover, a solid dispersion (weight ratio 1:9) of TSIIA with lowmolecular-weight chitosan (molecular weight $3.0 \times 10^{3}$, degree of deacetylation $90 \%$ ) was developed and evaluated the in vitro dissolution and in vivo performance. At $1 \mathrm{~h}$, the extent of dissolution of TSIIA increased about $368.2 \%$ compared with the pure drug. In vivo test showed that TSIIA solid dispersion system presented a larger $\mathrm{AUC}_{0-\mathrm{t}}$, which was 0.67 times that of physical mixtures and 1.17 times that of pure TSIIA. Additionally, the solid dispersion generated obviously higher $\mathrm{C}_{\max }$ and shortened $\mathrm{T}_{\max }$ compared with TSIIA and physical, which may be attributed to the rapid absorption rate resulting from the high dispersion of TSIIA in the carrier by potentiating its dissolution and to the absorption-enhancing effect of chitosan. As a result the relative bioavailability (\%) of physical mixture was $130 \%$, while that of the solid dispersion was $217 \%$ [86].

Nano formulations based on stealth (modified by Poloxamer 188) or non-stealth TSIIA-loaded solid lipid nanoparticles (TSIIASSLNs and TSIIA-NSSLNs, respectively) were developed and compared for the in vivo pharmacokinetics with unformulated TSIIA, after a single dose i.v. injection to rat of a dose corresponding to $1.33 \mathrm{mg} / \mathrm{kg}$ [87]. AUCS of TSIIA-NSLNs and TSIIA-SSLNs were 1.28 and 3.70 times than that of TSIIA, respectively. TSIIA-SSLNs had generated a long circulating time in the blood with a mean residence time of $5.286 \mathrm{~h}$, compared to the value of $3.051 \mathrm{~h}$ of TSIIANSLNs and of $0.820 \mathrm{~h}$ for TSIIA. As expected, Poloxamer 188 modification on SLNs reduced opsonization by serum proteins and the macrophage uptake, exhibiting much longer circulation lifetimes for TSIIA with respect to non-stealth formulations [87].

In a further pharmacokinetic study, CTS-loaded SLNs (prepared with glyceryl monosteatrate, GMS-SLNs, or Compritol 888 ATO, CP-SNLs, as lipid matrices) were orally administered in rats at single dose of $16 \mathrm{mg} / \mathrm{kg}$. The GMS-SLNs and CP-SLNs resulted in a higher $\mathrm{C}_{\max }(49.82$ and $53.68 \mu \mathrm{g} / \mathrm{ml}$, respectively.) of CTS compared with the CTS suspension $(20.89 \mu \mathrm{g} / \mathrm{ml})$. The $\mathrm{AUC}_{0-\infty}$ of CTS of GMS-SLNs and CP-SLNs were 1.86 and 2.05 times higher than those obtained with the CTS suspension. The relative bioavailability (\%) of CTS in the SLNs was significantly increased compared 
with that of a CTS suspension; it was between ca. 185\% and 205\%. Finally, the incorporation of CTS in SLNs also decreased the metabolism of CTS to TSIIA [88].

Moreover, a pharmacokinetic study was carried out with an inclusion complex of CTS and hydroxylpropyl-beta-cyclodextrin in dogs and rats [89]. The bioavailability of CTS in rats was ca. $6.9 \%$ at a dose of $60 \mathrm{mg} / \mathrm{kg}$ and ca. $11.1 \%$ in dogs at a dose of $53.4 \mathrm{mg} /$ $\mathrm{kg}$. The $\mathrm{t}_{1 / 2}$ of the compound in rats and dogs was $5.3-7.4 \mathrm{~h}$ and 6.0-10.0 h, respectively. CTS showed a high accumulation in the intestine, lungs, and liver after oral administration, while the lungs, liver, and heart had the highest level following i.v. administration. Excretion data in rats showed that CTS and its metabolites were mainly eliminated from feces and bile, and the dose recovery rate was $0.02,2.2$, and $14.9 \%$ in urine, bile, and feces, respectively [89].

Similarly, the effect of 2-hydroxypropyl- $\beta$-cyclodextrin on the aqueous solubility, dissolution rate, and intestinal permeability of the TSIIA was investigated. The inclusion complex $(1: 1)$ increased the aqueous solubility of TSIIA 17 times. The permeability rates of TSIIA across the intestinal epithelial membrane were enhanced by the inclusion complex about 5.2, 5.8, and 4.8 times of the uncomplexed TSIIA in the duodenum, jejunum, and ileum, respectively [90].

Besides the extensive studies reporting on the biological mechanisms of depsides and tanshinones, pharmacokinetics studies are still very limited and not conclusive. Clearly, the oral bioavailability of both depsides and tanshinones is quite low, because depsides are not stable, while tanshinones are very lipophic molecules with scarce absorption. Depsides have a high protein binding and metabolize very rapidly. If concomitantly administered, the bioavailability of both is enhanced, as reported in a unique study. It was reported that both classes of constituents can pass through the BBB after oral administration, but studies concerning brain distribution after administration of extracts, isolated constituents, or preparations are almost completely lacking. A few formulations of tanshinones, in particular SLN, can significantly improve their bioavailability. However, the pharmacokinetic and bioavailability studies reported in the literature cannot directly link the data from pharmacological assays to clinical effects and, consequently, aid the design of rational dosage regimens.

\section{Concluding Remarks}

$\nabla$

Modern science has considered S. miltiorrhiza a sort of a gold bullet, a panacea, and hundreds of studies have been performed to demonstrate various mechanisms of actions and possible implications in different therapeutic approaches. Attention has been mainly related to tanshinones and depsides, even if recently another class of constituents, the fraction of polysaccharides, has also been successfully investigated in rats $(125,250,500 \mathrm{mg} / \mathrm{kg} /$ day, 10 days by gavage) in models of global cerebral I/R injury [91].

Both depsides and tanshinones are safe with multiple pharmacological actions and they may act at multiple molecular targets. Various in vivo and in vitro studies support a possible role of these different constituents to treat CNS neuronal injury and degeneration. The different mechanisms can have an important role in the different pathologies, both the acute ones such as stroke and cerebral ischemia, traumatic brain injury, and epilepsy, and also chronic CNS diseases such as multiple sclerosis, AD, Parkinson's disease, schizophrenia, and so on.

\section{Conflict of Interest}

$\nabla$

The authors declare no conflict of interest.

References

1 Hao J, He X, Huang L, Chen M. Materia Medica and plant resource. In: Yan X, editor. Dan Shen (Salvia miltiorrhiza) in Medicine, Vol. 1. Dordrecht: Springer; 2015: 1-10

2 Wang $B Q$. Salvia miltiorrhiza: Chemical and pharmacological review of a medicinal plant. J Med Plants Res 2010; 4: 2813-2820

3 Chinese Pharmacopoeia Commission. Pharmacopoeia of the People's Republic of China, Vol. 1. Beijing: People's Medical Publishing House; 2005: 213

4 Zhou L, Zuo Z, Chow MSS. Danshen: an overview of its chemistry, pharmacology, pharmacokinetics, and clinical use. J Clin Pharmacol 2005; 45: $1345-1349$

5 Chace C, Liang ZT, Bowei AQ. Anthology. Brookline MA: Paradigm Publications; 1997

6 Lei XL, Chiou GCY. Studies on cardiovascular actions of Salvia miltiorrhiza. Am J Chin Medicine 1986; 14: 26-32

7 Lei XL, Chiou GCY. Cardiovascular pharmacology of Panax notoginseng and Salvia miltiorrhiza. Am J Chin Medicine 1986; 14: 145-152

8 Lee YW, Kim DH, Jeon SJ, Park SJ, Kim JM, Jung JM, Lee HE, Bae SG, Oh HK, Son $\mathrm{KH}, \mathrm{Ryu} \mathrm{JH}$. Neuroprotective effects of salvianolic acid B on an A $325-35$ peptide-induced mouse model of Alzheimer's disease. Eur J Pharmacol 2013; 704: 70-77

9 Zhu H, Zou L, Tian J, Du G, Gao Y. SMND-309, a novel derivative of salvianolic acid $B$, protects rat brains ischemia and reperfusion injury by targeting the JAK2/STAT3 pathway. Eur J Pharmacol 2013; 714: 23-31

10 Hügel HM, Jackson N. Danshen diversity defeating dementia. Bioorg Med Chem Lett 2014; 24: 708-716

11 Jiang YF, Liu ZQ Cui W, Zhang WT, Gong JP, Wang XM, Zhang Y, Yang MJ. Antioxidant effect of salvianolic acid B on hippocampal CA1 neurons in mice with cerebral ischemia and reperfusion injury. Chin J Integr Med, 31 July 2014 [Epub ahead of print]; DOI: DOI: 10.1007/s11655-0141791-1

12 Cao YY, Wang L, Ge H, Lu XL, Pei Z, Gu Q Xu J. Salvianolic acid A, a polyphenolic derivative from Salvia miltiorrhiza bunge, as a multifunctional agent for the treatment of Alzheimer's disease. Mol Divers 2013; 17: $515-524$

13 Guo Y, Li Y, Xue L, Severino RP, Gao S, Niu J, Qin LP, Zhang D, Brömme D. Salvia miltiorrhiza: an ancient Chinese herbal medicine as a source for anti-osteoporotic drugs. J Ethnopharmacol 2014; 155: 1401-1416

14 Chen $\mathrm{Z}, \mathrm{Xu} \mathrm{H}$. Anti-inflammatory and immunomodulatory mechanism of tanshinone IIA for atherosclerosis. Evid Based Complement Alternat Med, 2 Dec 2014 [Epub ahead of print]; DOI: DOI: 10.1155/2014/ 267976

15 Jin Q Jiang S, Wu YL, Bai T, Yang Y, Jin X, Lian LH, Nan JX. Hepatoprotective effect of cryptotanshinone from Salvia miltiorrhiza in D-galactosamine/lipopolysaccharide-induced fulminant hepatic failure. Phytomedicine 2014; 21: 141-147

16 Lu L, Li C, Li D, Wang Y, Zhou C, Shao W, Peng J, You Y, Zhang X, Shen X. Cryptotanshinone inhibits human glioma cell proliferation by suppressing STAT3 signaling. Mol Cell Biochem 2013; 381: 273-282

17 Huang L, Chen M, Guo L. Distribution and habitat of Danshen. In: Yan X, editor. Dan Shen (Salvia miltiorrhiza) in Medicine, Vol. 1. Dordrecht: Springer; 2015: 11-18

18 Liu M, Li Y, Chou G, Cheng X, Zhang M, Wang Z. Extraction and ultra-performance liquid chromatography of hydrophilic and lipophilic bioactive components in a Chinese herb Radix Salviae Miltiorrhizae. J Chromatogr A 2007; 1157: 51-55

19 Song JZ, Qiao CF, Li SL, Han QB, Xu HX. Quality assessment of granule of Danshen extract by high performance liquid chromatography. Chin J Nat Med 2009; 7: 368-375

20 Mei Z, Zhang F, Tao L, Zheng W, Cao Y, Wang Z, Tang S, Le K, Chen S, Pi R, Liu P. Cryptotanshinone, a compound from Salvia miltiorrhiza modulates amyloid precursor protein metabolism and attenuates $\beta$-amyloid deposition through upregulating-secretase in vivo and in vitro. Neurosc Lett 2009; 452: 90-95

21 Park OK, Choi JH, Park J, Kim IH, Yan BC, Ahn JH, Kwon SH, Lee JC, Kim YS, Kim M, Kang IJ, Kim JD, Lee YL, Won MH. Comparison of neuroprotective effects of five major lipophilic diterpenoids from Danshen extract against experimentally induced transient cerebral ischemic damage. Fitoterapia 2012; 83: 1666-1674 
22 Wang L, Zhang X, Liu L, Cui L, Yang R, Li M, Du W. Tanshinone II A downregulates HMGB1, RAGE, TLR4, NF- $k$ B expression, ameliorates BBB permeability and endothelial cell function, and protects rat brains against focal ischemia. Brain Res 2010; 1321: 143-151

23 Lam BYH, Lo ACY, Sun X, Luo HW, Chung SK, Sucher NJ. Neuroprotective effects of tanshinones in transient focal cerebral ischemia in mice. Phytomedicine 2003; 10: 286-291

24 Liu L, Zhang X, Wang L, Yang R, Cui L, Li M, Du W, Wang S. The neuroprotective effects of Tanshinone IIA are associated with induced nuclear translocation of TORC1 and upregulated expression of TORC1, pCREB and BDNF in the acute stage of ischemic stroke. Brain Res Bull 2010; 82: $228-233$

25 Tang C, Xue H, Bai C, Fu R, Wu A. The effects of Tanshinone IIA on bloodbrain barrier and brain edema after transient middle cerebral artery occlusion in rats. Phytomedicine 2010; 17: 1145-1149

26 Liu X, An C, Jin P, Liu X, Wang L. Protective effects of cationic bovine serum albumin-conjugated PEGylated tanshinone IIA nanoparticles on cerebral ischemia. Biomaterials 2013; 34: 817-830

27 Zhou L, Bondy SC, Jian L, Wen P, Yang F, Luo H, Li W, Zhou J. Tanshinone IIA attenuates the cerebral ischemic injury-induced increase in levels of GFAP and of caspases-3 and -8. Neuroscience 2015; 288 C: 105-111

28 Guo C, Yin Y, Duan J, Zhu Y, Yan J, Wei G, Guan Y, Wu X., Wang Y, Xi M, Wen A. Neuroprotective effect and underlying mechanism of sodium danshensu [3-(3,4-dihydroxyphenyl) lactic acid from Radix and Rhizoma Salvia miltiorrhiza $=$ Danshen $]$ against cerebral ischemia and reperfusion injury in rats. Phytomedicine 2015; 22: 283-289

29 Tian J, Fu F, Li G, Gao Y, Zhang Y, Meng Q Li C, Liu F. Protections of SMND-309, a novel derivate of salvianolic acid B, on brain mitochondria contribute to injury amelioration in cerebral ischemia rats. Phytomedicine 2009; 16: 726-733

30 Cao ZQ Quan W, Hou SX, Guo C, Ma SB, Zhang W, Li X. The natural therapeutic magnesium lithospermate B potently provides neuroprotective effects on cerebral ischemia/reperfusion injury in rats. J Ethnopharm 2015; 162: 191-198

31 Wang T, Fu F, Han B, Zhang L, Zhang X. Danshensu ameliorates the cognitive decline in streptozotocin-induced diabetic mice by attenuating advanced glycation end product-mediated neuroinflammation. J Neuroimmun 2012; 245: 79-86

32 Kim DH, Park SJ, Kim JM, Jeon SJ, Kim DH, Cho YK, Son KH, Lee HJ, Moon $J H$, Cheong JH, Ko KH, Ryu JH. Cognitive dysfunctions induced by a cholinergic blockade and $\mathrm{Ab}(25-35)$ peptide are attenuated by salvianolic acid B. Neuropharmacology 2011; 61: 1432-1440

33 Lee YW, Kim DH, Jeon SJ, Park SJ, Kim JM, Jung JM, Lee HE, Bae SG, Oh HK, Son $\mathrm{KHH}, \mathrm{Ryu} \mathrm{JH}$. Neuroprotective effects of salvianolic acid B on an Ab25-35 peptide-induced mouse model of Alzheimer's disease. Eur J Pharmacol 2013; 704: 70-77

34 Xia SF, Xie ZX, Qiao Y, Li LR, Cheng XR, Duan XM, Tang X, Shi YH, Le GW. Salvianolic acid $B$ counteracts cognitive decline triggered by oxidative stress in mice fed with high-fat diets. J Funct Foods 2014; 11: 278-292

35 Liu X, Ye M, An C, Pan L, Ji L. The effect of cationic albumin-conjugated PEGylated tanshinone IIA nanoparticles on neuronal signal pathways and neuroprotection in cerebral ischemia. Biomaterials 2013; 34: 6893-6905

36 Yu XY, Lin SG, Zhou ZW, Chen X, Liang J, Duan W, Yu XQ Wen JY, Chowbay $B$, Li CG, Sheu FS, Chan E, Zhou SF. Tanshinone IIB, a primary active constituent from Salvia miltiorrhza, exhibits neuro-protective activity in experimentally stroked rats. Neurosc Lett 2007; 417: 261-265

37 Chen Y, Wu X, Yu S, Fauzee NJ, Wu J, Li L, Zhao J, Zhao Y. Neuroprotective capabilities of Tanshinone IIA against cerebral ischemia/reperfusion injury via anti-apoptotic pathway in rats. Biol Pharm Bull 2012; 35: 164-170

38 Wang L, Zhang X, Liu L, Cui L, Yang R, Li M, Du W. Tanshinone IIA downregulates HMGB1, RAGE, TLR4, NF- $k$ B expression, ameliorates BBB permeability and endothelial cell function, and protects rat brains against focal ischemia. Brain Res 2010; 1321: 143-151

39 Qian $Y H$, Xiao $Q$ Xu J. The protective effects of tanshinone IIA on $\beta$-amyloid protein (1-42)-induced cytotoxicity via activation of the Bcl-xL pathway in neuron. Brain Res Bull 2012; 88: 354-358

40 Shi LL, Yang WN, Chen XL, Zhang JS, Yang PB, Hu XD, Han H, Qian YH, Liu $Y$. The protective effects of tanshinone IIA on neurotoxicity induced by $\beta$-amyloid protein through calpain and the $\mathrm{p} 35 / \mathrm{Cdk} 5$ pathway in primary cortical neurons. Neurochem Int 2012; 61: 227-235

41 Fan GW, Gao XM, Wang H, Zhu Y, Zhang J, Hu LM, Su YF, Kang LY, Zhang $B L$. The anti-inflammatory activities of Tanshinone IIA, an active com- ponent of TCM, are mediated by estrogen receptor activation and inhibition of iNOS. J Steroid Biochem Mol Biol 2009; 113: 275-280

42 Chen Y, Wu X, Yu S, Lin X, Wu J, Li L, Zhao J, Zhao Y. Neuroprotection of tanshinone IIA against cerebral ischemia/reperfusion injury through inhibition of macrophage migration inhibitory factor in rats. PLoS One 2012; 7: e40165

43 Zhou LH, Hu Q, Sui H, Ci SJ, Wang Y, Liu X, Liu NN, Yin PH, Qin JM, Li Q. Tanshinone II-a inhibits angiogenesis through down regulation of COX-2 in human colorectal cancer. Asian Pac J Cancer Prev 2012; 13: $4453-4458$

44 Xing Y, Tu J, Zheng L, Guo L, Xi T. Anti-angiogenic effect of tanshinone IIA involves inhibition of the VEGF/VEGFR2 pathway in vascular endothelial cells. Oncol Rep 2015; 33: 163-170

45 Wang $Q$ Yu X, Patal K, Hu R, Chuang S, Zhang G, Zheng J. Tanshinones inhibit amyloid aggregation by amyloid- $\beta$ peptide, disaggregate amyloid fibrils, and protect cultured cells. ACS Chem Neurosci 2013; 4: 1004-1015

46 Zhou Y, Li W, Xu L, Chen L. In Salvia miltiorrhiza, phenolic acids possess protective properties against amyloid $\beta$-induced cytotoxicity, and tanshinones act as acetylcholinesterase inhibitors. Environ Toxicol Pharmacol 2011; 31: 443-452

47 Liu T, Jin H, Sun QR, Xu JH, Hu HT. The neuroprotective effects of tanshinone IIA on $\beta$-amyloid-induced toxicity in rat cortical neurons. Neuropharmacology 2010; 59: 595-604

48 Park JH, Park Ok, Cho JH, Chen BH, Kim IH, Ahn JH, Lee JC, Yan BC, Yoo KY, Lee CH, Hwang IK, Kwon SH, Lee YL, Won MH, Choi JH. Anti-inflammatory effect of tanshinone I in neuroprotection against cerebral ischemia-reperfusion injury in the gerbil hippocampus. Neurochem Res 2014; 39: 1300-1312

49 Tung YT, Chen HL, Lee CY, Chou YC, Lee PY, Tsai HC, Lin YL, Chen CM. Active component of Danshen (Salvia miltiorrhiza Bunge), tanshinone I attenuates lung tumorigenesis via inhibitions of VEGF, cyclin A, and cyclin B Expressions. Evid Based Complement Alternat Med 2013; 2013: 319247

50 Mei Z, Situ B, Tan X, Zheng S, Zhang F, Yan P, Liu P. Cryptotanshinione upregulates $\alpha$ secretase by activation PI3 K pathway in cortical neurons. Brain Res 2010; 1348: 165-173

51 Kim DH, Jeon SJ, Jung JW, Lee S, Yoon BH, Shin BY, Son KH, Cheong JH, Kim YS, Kang SS, Ko KH, Ryu JH. Tanshinone congeners improve memory impairments induced by scopolamine on passive avoidance tasks in mice. Eur J Pharm 2007; 574: 140-147

52 Jin HJ, Xie XL, Ye JM, Li CG. TanshinoneIIA and cryptotanshinone protect against hypoxiainduced mitochondrial apoptosisin H9c2 cells. PLoS One 2013; 8: e51720

53 Lin YH, Liu AH, Wu HL, Westenbroek C, Song QL, Yu HM, Ter Horst GJ, Li $X J$. Salvianolic acid B, an antioxidant from Salvia miltiorrhiza, prevents Abeta(25-35)-induced reduction in BPRP in PC12 cells. Biochem Biophys Res Commun 2006; 348: 593-599

54 Tian LL, Wang XJ, Sun YN, Li CR, Xing YL, Zhao HB, Duan M, Zhou Z, Wang $S Q$. Salvianolic acid B, an antioxidant from Salvia miltiorrhiza, prevents 6-hydroxydopamine induced apoptosis in SH-SY5Y cells. Int J Biochem Cell Biol 2008; 40: 409-422

55 Chen T, Liu W, Chao X, Zhang L, Qu Y, Huo J, Fei Z. Salvianolic acid B attenuates brain damage and inflammation after traumatic brain injury in mice. Brain Res Bull 2011; 84: 163-168

56 Durairajan SS, Yuan Q Xie L, Chan WS, Kum WF, Koo I, Liu C, Song Y, Huang JD, Klein WL, Li M. Salvianolic acid B inhibits Abeta fibril formation and disaggregates preformed fibrils and protects against Abeta-induced cytotoxicty. Neurochem Int 2008; 52: 741-750

57 Wang XJ, Xu JX. Salvianic acid A protects human neuroblastoma SHSY5Y cells against MPP+-induced cytotoxicity. Neurosci Res 2005; 51: $129-138$

58 Zhang H, Liu YY, Jiang Q Li KR, Zhao YX, Cao C, Yao J. Salvianolic acid A protects RPE cells against oxidative stress through activation of Nrf2/ HO-1 signaling. Free Radic Biol Med 2014; 69: 219-228

59 Wang T, Fu F, Han B, Zhang L, Zhang X. Danshensu ameliorates the cognitive decline in streptozotocin-induced diabetic mice by attenuating advanced glycation end product-mediated neuroinflammation. J Neuroimmunol 2012; 245: 79-86

60 Alkam T, Nitta A, Mizoguchi H, Itoh A, Nabeshima T. A natural scavenger of peroxynitrites, rosmarinic acid, protects against impairment of memory induced by $\mathrm{A} \beta_{25-35}$. Behav Brain Res 2007; 180 : 139-145

61 Renzulli C, Galvano F, Pierdomenico L, Speroni E, Guerra MC. Effects of rosmarinic acid against aflatoxin B1 and ochratoxin-A-induced cell 
damage in a human hepatoma cell line (Hep G2). J Appl Toxicol 2004; 24: $289-296$

62 Ono K, Hasegawa K, Naiki H, Yamada M. Curcumin has potent antiamyloidogenic effects for Alzheimer's A fibrils in vitro. J Neurosci Res 2004; 75: 742-750

63 Iuvone T, De Filippis D, Esposito G, D'Amico A, Izzo AA. The spice sage and its active ingredient rosmarinic acid protect PC12 cells from amyloidbeta peptide-induced neurotoxicity. J Pharmacol Exp Ther 2006; 317: 1143-1149

64 Lucas SM, Rothwell NJ, Gibson RM. The role of inflammation in CNS injury and disease. Br J Pharmacol 2006; 147: S232-S240

65 Lehtinen MK, Bonni A. Modeling oxidative stress in the central nervous system. Curr Mol Med 2006; 6: 871-881

66 Mattson MP. Apoptosis in neurodegenerative disorders. Nat Rev Mol Cell Biol 2000; 1: 120-129

67 McCloskey DP, Croll SD, Scharfman HE. Depression of synaptic transmission by vascular endothelial growth factor in adult rat hippocampus and evidence for increased efficacy after chronic seizures. J Neurosci 2005; 25: 8889-8897

68 Steiner J, Schiltz K, Bernstein HG, Bogerts B. Antineuronal antibodies against neurotransmitter receptors and synaptic proteins in schizophrenia: current knowledge and clinical implications. CNS Drugs 2015; 29: 197-206

69 Jia JY, Lu YL, Li XC, Liu GY, Li SJ, Liu Y, Liu YM, Yu C, Wang YP. Pharmacokinetics of depside salts from Salvia miltiorrhiza in healthy Chinese volunteers: A randomized, open-label, single-dose study. Curr Ther Res Clin Exp 2010; 71: 260-271

70 Guo ZJ, Zhang Y, Tang X, Li H, Sun QS. Pharmacokinetic interaction between tanshinones and polyphenolic extracts of Salvia miltinorrhiza Bunge after intravenous administration in rats. Biol Pharm Bull 2008; 31: 1469-1474

71 Zhang YJ, Wu L, Zhang QL, Li J, Yin FX, Yuan Y. Pharmacokinetics of phenolic compounds of Danshen extract in rat blood and brain by microdialysis sampling. J Ethnopharmacol 2011; 136: 129-136

72 Sun J, Zhang L, Song J, Tian S, Huang C, Feng Z, Lv Y, Du G. Pharmacokinetic study of salvianolic acid $A$ in beagle dog after oral administration by a liquid chromatography-mass spectrometry method: a study on bioavailability and dose proportionality. J Ethnopharmacol 2013; 148 : 617-623

73 Hou YY, Peng JM, Chao RB. Pharmacokinetic study of salvianolic acid A in rat after intravenous administration of Danshen injection. Biomed Chromatogr 2007; 21: 598-601

74 Wang L, Zhang Q Li X, Lu Y, Xue Z, Xuan L, Wang Y. Pharmacokinetics and metabolism of lithospermic acid by LC/MS/MS in rats. Int J Pharm 2008; 350: 240-246

75 Li XC, Yu C, Sun WK, Liu GY, Jia JY, Wang YP. Pharmacokinetics of magnesium lithospermate $B$ after intravenous administration in beagle dogs. Acta Pharmacol Sin 2004; 25: 1402-1407

76 Chen YF, Jaw I, Shiao MS, Tsai TH. Determination and pharmacokinetic analysis of salvianolic acid $\mathrm{B}$ in rat blood and bile by microdialysis and liquid chromatography. J Chromatogr A 2005; 1088: 140-145

77 Li J, Wang G, Li P, Hao H. Simultaneous determination of tanshinone IIA and cryptotanshinone in rat plasma by liquid chromatography-electrospray ionization-mass spectrometry. J Chromatogr B 2005; 826: 26-30
78 Song M, Hang TJ, Zhang ZH, Du R, Chen J. Determination of cryptotanshinone and its metabolite in rat plasma by liquid chromatography-tandem mass spectrometry. J Chromatogr B 2005; 827: 205-209

79 Hao H, Wang G, Li P, Li J, Ding Z. Simultaneous quantification of cryptotanshinone and its active metabolite tanshinone IIA in plasma by liquid chromatography/tandem mass spectrometry (LCMS/MS). J Pharm Biom Anal 2006; 40: 382-388

80 Sun J, Yang M, Wang X, Xu M, Liu A, Guo D. Identification of tanshinones and their metabolites in rat bile after oral administration of TTE-50, a standardized extract of Salvia miltiorrhiza by HPLC-ESI-DAD-MSn. J Pharm Biom Anal 2007; 44: 564-574

81 Li P, Wang GJ, Li J, Hao HP, Zheng CN. Characterization of metabolites of tanshinone IIA in rats by liquid chromatography/tandem mass spectrometry. J Mass Spectrom 2006; 41: 670-684

82 Park E, Ji HY, Kim NJ, Song WY, Kim YH, Kim YC, Sohn DH, Lee HS. Simultaneous determination of tanshinone I, dihydrotanshinone I, tanshinone IIA and cryptotanshinone in rat plasma by liquid chromatography-tandem mass spectrometry: application to a pharmacokinetic study of a standardized fraction of Salvia miltiorrhiza, PF2401-SF. Biomed Chromatogr 2008; 22: 548-555

83 Hao H, Wang G, Cui N, Li J, Xie L, Ding Z. Pharmacokinetics, absorption and tissue distribution of tanshinone IIA solid dispersion. Planta Med 2006; 72: 1311-1317

$84 \mathrm{Yu}$ H, Subedi RK, Nepal PR, Kim YG, Choi HK. Enhancement of solubility and dissolution rate of cryptotanshinone, tanshinone I and tanshinone IIA extracted from Salvia miltiorrhiza. Arch Pharm Res 2012; 35: 1457 1464

85 Li J, Liu P, Liu JP, Zhang WL, Yang JK, Fan YQ. Novel Tanshinone II A ternary solid dispersion pellets prepared by a single-step technique: in vitro and in vivo evaluation. Eur J Pharm Biopharm 2012; 80: 426-432

86 Liu $Q Y$, Zhang ZH, Jin X, Jiang YR, Jia XB. Enhanced dissolution and oral bioavailability of tanshinone IIA base by solid dispersion system with low-molecular-weight chitosan. J Pharm Pharmacol 2013; 65: 839846

87 Zhang WL, Liu JP, Liu XX, Chen ZQ. Stealth tanshinone IIA-loaded solid lipid nanoparticles: effects of poloxamer 188 coating on in vitro phagocytosis and in vivo pharmacokinetics in rats. Yao Xue Xue Bao 2009; 44: $1421-1428$

$88 \mathrm{Hu}$ LD, Xing Q Meng J, Shang C. Preparation and enhanced oral bioavailability of cryptotanshinone-loaded solid lipid nanoparticles. AAPS PharmSciTech 2010; 11: 582-587

89 Pan Y, Bi HC, Zhong GP, Chen X, Zuo Z, Zhao LZ, Gu LQ Liu PQ Huang ZY, Zhou SF, Huang M. Pharmacokinetic characterization of hydroxylpropyl-beta-cyclodextrin-included complex of cryptotanshinone, an investigational cardiovascular drug purified from Danshen (Salvia miltiorrhiza). Xenobiotica 2008; 38: 382-398

90 Wang L, Jiang X, Xu W, Li C. Complexation of tanshinone IIA with 2-hydroxypropyl- $\beta$-cyclodextrin: effect on aqueous solubility, dissolution rate, and intestinal absorption behavior in rats. Int J Pharm 2007; 341: 58-67

91 Tu Q Wang R, Ding B, Zhong W, Cao H. Protective and antioxidant effect of Danshen polysaccharides on cerebral ischemia/reperfusion injury in rats. Int J Biol Macromol 2013; 60: 268-271 